\title{
ENSAYO DE UNA NUEVA EXPOSICIÓN DE LA DOCTRINA DE LA CIENCIA - UN FRAGMENTO DE FILOSOFÍA ${ }^{1}$
}

\section{AN ATTEMPT AT A NEW PRESENTATION OF THE DOCTRINE OF SCIENCE-A FRAGMENT OF PHILOSOPHY}

\author{
VASCO DE JESUS \\ Universidade Nova de Lisboa
}

I.

La idea de que el único modo de especificar totalmente un concepto presupone la identificación del acto a través del cual el concepto se constituye ${ }^{2}$ es un

\footnotetext{
${ }^{1}$ Quisiera agradecer a la Unidade de Investigação I\&D «Linguagem, Interpretação e Filosofia» (LIF) de la Universidade de Coimbra y en particular al profesor António Manuel Martins por el apoyo incondicional que me ha mostrado y por hacer posible mi participación en esta acción de la RIEF. Una palabra especial de agradecimiento se la debo también al profesor Jacinto Rivera de Rosales por su amistad y por la invitación a que estuviera presente en estas jornadas filosóficas. Tampoco podría dejar de mencionar a Óscar Cubo y agradecerle por el tiempo y el cuidado que le ha dispensado a la revisión de mi texto en la fase final de este proceso. Por último, son muy escasos los recursos de los que dispongo para expresarle mi gratitud al profesor Mário Jorge de Carvalho. Algunos niños usan cada pocos días una palabra nueva. Yo no me arriesgaría tanto en este idioma. «Hay ineptos entusiastas.» — dice Lichtenberg— «Gente muy peligrosa.» Por eso, aunque no sean mías, echo mano de palabras antiguas que, como ante un espejo, siempre me harán volver sobre mí mismo - comprendo lo que dicen y dicen lo que pienso: "Sed ex inbecillitate uestra coniecturam capitis ingentis animi». Quisiera empero decir que permanezco en deuda. Bem hajam.

2 «Nur dadurch, daß man den Act angiebt, durch welchen ein Begriff zu Stande kommt, wird derselbe vollkommen bestimmt.», VND, GA I/4, 272. Todas las referencias remiten a la edición de la obra completa de Fichte: GA J. G. Fichte-Gesamtausgabe der Bayerischen Akademie der Wissenschaften. R. Lauth †, H. Gliwitzky †, H. Jacob †, E. Fuchs, P. K. Schneider y G. Zöller (eds.). Stuttgart-Bad Cannstatt, Frommann-Holzboog, 1962 ss.
} 
Leitmotif del lo que se ha estipulado llamar «el Fichte de Jena». Pues bien, el objetivo de este artículo es hacer una breve recapitulación de las líneas directrices de dicho procedimiento tal y como son trazadas por Fichte en su Ensayo de una nueva exposición de la Doctrina de la Ciencia (Versuch einer neuen Darstellung der Wissenschaftslehre $)^{3}$.

Nuestra investigación incide inicialmente sobre la posibilidad de reconstituir el acto que está en el origen del concepto «yo». Por lo tanto, nos proponemos averiguar de qué modo el concepto del «yo» se constituye para el sujeto (empírico). Lo que se indaga son las condiciones de posibilidad del concepto tal y como es pensado en el horizonte de la experiencia, o sea, desde el punto de vista de la vida (Standpunkt des Lebens). A pesar de no ser aún una reflexión desde el punto de vista transcendental, lo que buscamos comprender en una primera fase es ¿en qué consiste, cómo se manifiesta y de qué modo es posible la consciencia de sí? y ¿qué relación hay entre la consciencia de objetos exteriores y la autoconsciencia?

Dirigiéndose al lector, Fichte parte del presupuesto de que cada uno de nosotros puede pensar el «yo» del siguiente modo: 1) cuando pienso «yo», aquello de lo que soy inmediatamente consciente es de que estoy haciendo algo, i.e., de que soy activo; y 2) cuando pienso "yo» me doy cuenta de que mi consciencia está internamente determinada de un modo especifico, a saber, por aquello que yo comprendo en correspondencia con el concepto al que mi acto de pensar se dirige. Si presto atención a estos dos aspectos (o sea, a la actividad y a la determinación que están envueltas en este proceso), puedo aún percibir 3) que entre todo aquello que podría igualmente estar pensando en este preciso momento, no estoy pensando en nada más que en el «yo», y 4) que soy yo el que limita o restringe esa misma actividad (es decir, no estoy obligado a pensar al «yo», pues nada ni nadie me impone pensar este concepto - sino que soy yo quien escoge producir justamente este y no un cualquier otro pensamiento) ${ }^{4}$.

\footnotetext{
${ }^{3}$ Siempre que sea oportuno y pueda contribuir para una más clara comprensión de dichos argumentos, buscaremos completar nuestro análisis recurriendo al mismo tiempo a algunos de los enunciados de la Erste Einleitung in die Wissenschaftslehre, Zweite Einleitung in die Wissenschaftslehre y la WLnm-K.

${ }^{4}$ Véase VND, GA I/4, 271. Debe observarse que la estrategia del Versuch es la de un entendimiento con el lector y que dicho entendimiento es buscado a través de ciertos «denominadores comunes». El lector no tiene que pensar todo exactamente como está indicado en el texto. Lo importante es que justo en lo que piensa se incluya también aquello que es indicado en el texto.
} 
Para comprender mejor de lo que aquí se trata, vamos a considerar algunos aspectos que, aunque no aparecen explícitamente en el Versuch, son mencionados por Fichte en otros textos de su obra. Pensar algo determinado - ¿qué tipo de acto es este, cómo puede ser realizado, qué es lo que está envuelto en él? Desde luego, este acto es un acto determinado que implica una elección (Wahl) por parte del sujeto. Soy yo, sujeto finito, quien lo realizo. Además, tiene que haber una esfera que corresponda a lo elegible (lo determinable, das Bestimmbare); o sea, debe haber una esfera que represente el ámbito de la totalidad posible de lo elegible. Por una parte, la posibilidad de realizar este acto tiene como condición que pueda estar dirigido hacia una multiplicidad (Mannigfaltigkeit); en efecto, la totalidad correspondiente al campo de lo elegible tiene que envolver una multiplicidad, pues de lo contrario no se podría hablar de la elección de algo particular como de un acto producido en libertad. Por otro lado, mi acto está limitado (gebunden/beschränkt) a esa misma esfera que comprende toda esa multiplicidad. O sea, mi libertad (la libertad de un sujeto racional finito) no se extiende en este caso a la decisión respecto de lo que deba o pueda estar (o no estar) comprendido en esa misma esfera de las elecciones posibles. Al contrario, lo que sucede es que mi libertad de pensar algo determinado tiene su punto de aplicación en esa multiplicidad (multiplicidad que se me ofrece o que yo encuentro dada o disponible), por lo que la elección no antecede (no es previa a) esa esfera, sino que tiene lugar cuando ya me encuentro arrojado e interesado en las posibilidades que integran y configuran el acontecimiento de la vida misma ${ }^{5}$.

De tal modo que el lector lo reconozca en sí, reconozca o bien tenga consciencia de ello en sí, reconozca dicha actividad y tenga consciencia de que es activo, reconozca que, cuando piensa y mientras que piensa algo, procede de un modo determinado, etc.

5 «Die Thätigkeit des Ich ist ein Uibergehen von der bloßen Bestimmbarkeit zur Bestimmtheit [.] Die leztere wird aus der Summe der ersten herausgerißen, und der herausgerißne Theil ist der der begriffen wird [...] Das Bestimmbare erscheint nicht als hervorgebracht, weder durch ideale noch durch reale Thätigkeit; es erscheint als gegeben zur Wahl [...] wir erhalten hier eine Summe des Bestimmbaren [...] Die Freiheit besteht darinn [,] daß unter allem gewählt werden kann, die Gebundenheit darinn, daß unter dieser Summe gewählt werden muß; wir erhalten hier den Begriff der bestimmten Summe für die Wahl der Freiheit; ein Theil der Summe heißt eine bestimmte Thätigkeit oder eine Handlung.», WLnm - K, GA IV/3, 368; "Die ideale Thätigkeit ist theils gebunden (bestimmt) theils frei. Die Freiheit ist das bedingte, und die Gebundenheit das Bedingende. Ist nichts gegeben [,] so kann nicht gewählt werden [...] Es ist der idealen Thätigkeit ein mannigfaltiges gegeben, aus diesem sezt sie einem Begriff zusammen, sie läßt liegen [,] was sie will, und faßt auf [,] was sie will; darinn besteht ihre Freiheit, aber das gegebene muß sie als gegeben anschauen und darin liegt ihre Gebundenheit.», WLnm - K, GA IV/3, 374. 
Pero esto no es todo. Hay que añadir aún el hecho de que la ley fundamental a la cual no puedo dejar de obedecer (en lo que concierne el ejercicio de mi libertad de pensar algo determinado) está para mí desde siempre ya decidida. Es decir, mí libertad tampoco se extiende a la decisión relativa a las leyes según las cuales yo tengo necesariamente que pensar, sea lo que sea, que yo he de pensar entre la multiplicidad que se me ofrece en el seno de esa esfera de lo elegible. Por lo tanto, se puede hablar de una limitación originaria (eine ursprüngliche Beschränkheit) de mi libertad para pensar algo determinado, o sea, una limitación insuperable 6 .

Ahora bien, un acto de pensar es siempre un acto de pensar determinado. Es decir, no puedo darme cuenta de que soy activo a no ser que al mismo tiempo encuentre algo que sea objeto de mi acción (en este caso, un objeto de pensamiento - aquello hacia lo que mi pensar se dispone (se orienta) y en relación con lo cual se determina), una vez que una actividad sin objeto es, esencialmente, indeterminada o está aún por determinar. Del mismo modo que, mientras todavía no se ha construido una imagen previa o un modelo prefigurativo (ein Vorbild) de lo que se pretende "producir» o alcanzar, el pensar sólo puede ser comprendido como determinable. O sea, no como una actividad determinada susceptible de ser reconocida como tal, sino como una actividad en reposo (ruhende Tätigkeit) o en tensión (Trieb) para un objeto posible. De tal modo que mientras tiene delante de si — como planeando en suspenso (schweben) — la indefinida multiplicidad de lo solamente posible (mientras no está dirigido a una posibilidad en particular), el pensamiento no está verdaderamente en acto, sino que está en un estado de relativo reposo o de tensión —en un estado, por así decirlo, de duda o indecisión (Zaudern,

\footnotetext{
${ }^{6}$ Es decir, por un lado se trata de algo necesario, o sea, algo que no es susceptible de ser ni convertido en algo de otro ni tampoco modificado, sino que siempre está - siempre tiene que estarpresente tal y como es (i.e., algo en sí mismo invariable). Por otro lado se trata de algo constituti$v o$ - dicha limitación es, por cierto, lo que es responsable del hecho de la escisión de la consciencia entre lo subjetivo y lo objetivo, algo que, para la consciencia, se haya siempre ya constituido y sin lo cual ella misma no sería pensable, i.e., no sería posible. Por lo tanto, se trata de algo que 1) no es ni derivado ni producido y que 2) no puede ser ni reconducido ni restituido a un estado previo, sino que es absolutamente primitivo, o sea, originario. Dicha limitación es condición de posibilidad necesaria de la consciencia, es la raíz misma (i.e., lo que está a la base) de la consciencia en cuanto acontecimiento de lucidez finito. Por consiguiente, se trata de algo que no puede ser disuelto, algo que no puede ser ni simplificado ni eliminado - es decir, se trata de algo irreductible.
} 
Unschlïssigkeit) con respecto a qué pensar. Sólo a través de la elección de una posibilidad, sólo a partir del momento en que el pensamiento asume una dirección cualquiera en virtud de su autodeterminación y de su libertad, sólo entonces la actividad ideal resulta determinada (por oposición a lo que antes constituía una indeterminación de esa misma actividad) — y sólo en ese momento se puede hablar de su determinidad (Bestimmtheit).

Por otro lado, la asunción de un objeto de pensamiento que conlleva la elección de una posibilidad consiste en un movimiento de transición (Übergehen) desde un estado de reposo (de ponderación o contemplación) hacia un «ser-en-acto». A través de este movimiento el pensamiento se sustrae (losreißen) a la indeterminación, construye para sí mismo un imagen de lo que pretende producir - imagen que capta como un concepto de fin (Zweckbegriff) - y, mediante una decisión o resolución, produce el tránsito de lo determinable a lo determinado. A la base de la consciencia de uno mismo como algo activo está, por lo tanto, siempre un darse cuenta de esta agilidad (Agilität). Por oposición a lo que pudiera ser un estado de absoluta pasividad (Leiden, Untätigkeit) —o sea, por oposición a lo que tiene que ser pensado como desprovisto de autodeterminación o espontaneidad-, dicha agilidad consiste en que el pensamiento puede elegir y protagonizar la adopción del objeto y del concepto de fin, determinándose como una instancia relativamente libre teniendo en cuenta los limites y las condiciones de posibilidad de su actividad. Dicho esto, volvemos sin más demora al texto del Versuch.

Justamente, que uno se percata de sí mismo como activo y de su actividad en cuanto piensa —es lo que Fichte pretende señalar cuando sugiere al lector que piense (el concepto de) «mesa», "pared», «ventana», en vez de pensar (el concepto de) «yo». La intención es el reconocimiento de una correlación necesaria (notwendige) entre un cierto modo de proceder y el respectivo resultado e inversamente entre un determinado contenido y un modo determinado de proceder. O sea, el reconocimiento de que el objeto de nuestro acto de pensar depende a la vez y en cada momento de la dirección estipulada para nuestro pensamiento. Si pensar es actuar y pensar es pensar algo determinado, entonces, si pienso (o cuando pienso) algo, he dirigido mi acto de pensar en una determinada dirección, me he conducido y he actuado de un modo determinado. Se trata, por lo tanto, de poner en evidencia que, con relación a la esfera de la totalidad de objetos posibles del pensar, el modo de actuar del sujeto no 
sólo condiciona lo que será elegido, sino también la naturaleza de lo que pueda ser encontrado. ${ }^{7}$

Todo esto nos permite percibir mejor lo que constituye el punto de partida de esta nueva exposición, a saber, la oposición (Entgegensetzung) fundamental entre el procedimiento (Verfahren) del pensar en el que la actividad del intelecto se vuelve o retorna sobre sí misma y aquel otro procedimiento del pensar en el cual, en vez de volverse sobre sí mismo, el pensamiento se dirige a la dirección contraria (o sea, al exterior, a lo que de inmediato suele ser considerado real). Lo que Fichte pone ahora al descubierto es la diferencia relativa a la dirección del acto de pensar. Dependiendo de si es una actividad que se vuelve o no sobre sí misma, así el pensamiento tendrá por objeto el «yo» o algo que no es «yo». Lo que está siendo delineado es, por lo tanto, la oposición entre el acto de pensar que se dirige hacia una actividad (más precisamente, a la propia actividad del pensar) y el acto de pensar que, por su naturaleza, no es la actividad propia del pensar (es decir, no es la actividad que lo piensa, sino algo otro que no es esa misma actividad). Si ese algo otro es activo o pasivo es algo que, por lo menos en el comienzo del Versuch, queda indeterminado (en el comienzo del texto no está aún presente la oposición entre actividad y pasividad; en el comienzo del texto sólo se trata de la oposición entre el procedimiento del pensar que se dirige al propio pensar en cuanto tal y el procedimiento del pensar que se dirige a otra "cosa» que no es la actividad misma del pensar, es decir, que no es la actividad ideal).

Ahora bien, aquí la clave es el contraste entre el procedimiento del pensar que tiene como correlato al yo y el procedimiento que no tiene como correlato

\footnotetext{
${ }^{7}$ Según Fichte la razón por la cual estoy pensando «X» y no, por ejemplo, «Y», se debe a que he actuado de tal modo que se ha producido el pensamiento de "X». Si, al pensar, yo hubiera actuado de un modo diferente, si hubiera pensado de otro modo, entonces aquello en lo que estaría pensando en este momento seria inevitablemente diferente. En consecuencia de mi modo de actuar, o bien tengo "X» o bien tengo "Y» como objeto de pensamiento. Del modo de pensar "X» resulta el pensamiento "X», del modo de pensar "Y» resulta el pensamiento "Y». Aquello que tenga como objeto de pensamiento sólo puede haber venido a la existencia para mí por medio del modo de pensar o del acto del pensamiento que lo produce. Por lo que se puede afirmar que lo que será producido ya está previamente anticipado o, por así decirlo, implicado por lo que había sido decidido. «Euer Denken ist ein Handeln, euer bestimmtes Denken ist sonach ein bestimmtes Handeln, d.h. das, was ihr denkt, ist gerade dieses, weil ihr im Denken gerade so handeltet; und es würde etwas anderes seyn (ihr würdet et wasanderes denken) wenn ihr in eurem Denken anders gehandelt hätte, (wenn ihr a n d e r s gedacht hättet).», VND, GA I/4, 271-272.
} 
al yo - esto es, el procedimiento que tiene como correlato la mesa, la pared o la ventana. Fichte se concentra en el primer procedimiento y deja por ahora fuera de consideración al segundo- así como la respectiva oposición. Sin duda que los procedimientos del pensar que tienen como correlato la mesa, la pared o la ventana también diferirán entre sí. Pero aquí Fichte sólo se concentra en lo que todos eses procedimientos tienen en común, a saber, aquello que nos permite distinguirlos de lo que sucede siempre que la actividad del pensar se vuelve o retorna sobre sí misma y se tiene a sí misma por objeto. De todos modos, un ponto es claro. Según Fichte, si la actividad del pensar no se vuelve sobre sí misma, puede tener muchos objetos. Si por lo contrario, se vuelve sobre sí misma, entonces no produce sino uno (o sea, siempre el mismo objeto), es decir, el concepto «yo». De modo que, además de la división (Trennung) entre sujeto y objeto, es posible reconocer una escisión (Spaltung) en el seno de la esfera de la objetividad, donde la diversidad y complejidad en la conformación de la multiplicidad que se presenta en esa misma esfera contrasta con la unidad y singularidad del otro objeto que surge para el sujeto siempre que su actividad de pensar se toma a sí misma como objeto ${ }^{8}$. Así, en un primer momento, se puede decir que, por un lado, todos los demás objetos constituirán algo exterior por oposición a ese "yo» que se constituye cuando la actividad del pensar se vuelve sobre sí misma; mientras que, por otro lado, sin que tenga lugar el volverse de la actividad del pensar sobre sí misma, no habrá nada que corresponda al concepto del «yo».

En suma, con independencia de lo que pueda estar en el origen de la diferencia entre lo que pienso cuando pienso "mesa», "pared» o "ventana», lo que es cierto es que a) cuando pienso algo como eso no actúo de aquel modo especifico que consiste en que la actividad del pensar se vuelve sobre sí misma, y a la inversa, que b) cuando se produce ese acto por el cual la actividad se vuelve sobre sí misma, dicho acto no produce sino el pensamiento del «yo» - y esto de tal modo que, por otro lado, el pensamiento del "yo» no consiste sino en la intuición de ese mismo acto, simplemente aprehendido como algo fijo (o sea, como concepto $)^{9}$. Es decir, el modo de pensar que está en el origen del concepto del

\footnotetext{
${ }^{8}$ Véase WLnm-K, GA IV/3, 373.

${ }^{9}$ "Also — der Begriff oder das Denken des Ich besteht in dem auf sich Handeln des Ich selbst; undumgekehrt, ein solches Handeln auf sich selbst giebt ein Denken des Ich, und schlech thin kein anderes Denken.», VND, GA I/4, 272. Una vez más, se trata de comprender que hay una correlación necesaria entre el acto y su resultado y, al inversa, entre lo que es producido por medio
} 
«yo» nos permite diferenciar de una sola vez su objeto de todos y cada uno de los objetos que pueden ser descubiertos por medio del modo de pensar que está en el origen de todo lo que no es "yo»" ${ }^{10}$.

La tarea que Fichte propone al lector es entonces la siguiente: hacerse consciente del modo como dirige o conduce su pensamiento cuando piensa el «yo» ${ }^{11}$. Por lo tanto, se trata de a) una tarea que consiste en enfocar, o sea, en hacer algo, en volverse activo, y de tal modo que b) dicha tarea consiste más precisamente en enfocar una actividad, es decir, en enfocar el modo de pensar que está en el origen del concepto de «yo» (i.e., el concepto sensible, el concepto del «yo» que el sujeto empírico siempre encuentra ya constituido y disponible). Con esto, queda sugerido que el procedimiento que está por detrás de la mencionada actividad puede pasar desapercibido, o sea, que dicha actividad (i.e., el pensarse a sí mismo) también puede producirse con un déficit de atención (ohne es zu merken), tal y como cuando actuamos — pensamos - sin tener plena consciencia de lo que lo estamos haciendo, i.e., sin tener plena consciencia de ¿qué? Y ¿cómo? lo estamos haciendo. Ahora bien, este déficit de atención es precisamente lo que se trata de suplir.

Para ello, Fichte propone que se considere lo que sucede cuando pensamos en la mesa o en la pared. En este caso, yo soy para mi mismo el sujeto del acto de pensar, aquel que hace algo, que actúa, que dirige su pensamiento, que se conduce de un cierto modo, que realiza una acción. Pero aquello hacia lo cual mi acto está dirigido (eso que es pensado o aprehendido en virtud de que mi pensamiento haya asumido una determinada dirección) no es la propia actividad del pensar, sino más bien algo diferente de ella. En este caso, sujeto y objeto son para mí claramente distintos; y en cualquier momento puedo producir esta distinción

de dicho acto y el modo especifico y determinado de proceder que está a su base. No sólo el concepto de «yo» es exclusivamente producido por el acto de pensar que se tiene a sí mismo por objeto, sino que también sólo es mediante este acto de pensar determinado como el concepto de "yo» se constituye.

${ }^{10}$ A pesar de que no esté inmediatamente claro lo que pueda estar en el origen de su diferencia, lo que sí está inmediatamente claro es que todos eses objetos tienen algo en común, a saber, formar parte de un todo (das NichtIch) que, en cuanto tal, es puesto en oposición a lo que tiene lugar en la esfera que resulta del modo de pensar el «yo».

${ }^{11}$ «meine Aufgabe an dich, verständiger Leser, ist die: dir eigentlich und innigst bewusst zu werden, w i e du verfährst, wenn du denkst: Ich.», VND, GA I/4, 272. 
(Unterscheidung): yo estoy pensando; pero no estoy pensando en mí, sino que estoy pensando en la pared; la pared es lo que es pensado por mí y lo que es pensado por mí es eso mismo de lo que soy consciente en cuanto algo objetivo - y aunque no tenga la consciencia de haberlo producido, sí tengo la consciencia de haber producido su representación. Por lo tanto, yo no soy el objeto, sino el sujeto de esta acción ${ }^{12}$.

Prestemos ahora nuestra atención a lo que ocurre cuando pensamos "yo». Cuando pienso «yo», el sujeto y el objeto de la acción coinciden. Desde luego, por medio de esta acción yo soy para mí, no simplemente sujeto del acto de pensar, no solamente activo, sino que también (y al mismo tiempo) eso mismo en lo cual estoy pensando, eso mismo que está siendo pensado por mí - es decir, yo soy también lo que es aprehendido. Soy simultáneamente sujeto y objeto de la acción, el que dirige su pensamiento y aquello hacia lo cual mi pensamiento se dirige. Por otro lado, y al contrario de lo que sucedía cuando pensaba en la pared, aquello en lo que ahora estoy pensando no está puesto delante de mí, fuera de mí, de tal modo que, por así decirlo, yo me sitúe de espaldas a mí mismo o tenga que salir de mí para salir a mi encuentro. Por el contrario, en lugar de consistir en un movimiento por el cual salgo de mí hacia un objeto exterior, el acto de pensarme a mí presupone un movimiento inverso. O sea, la posibilidad de pensar el «yo» conlleva para mí un volverme sobre mí mismo, un acto a través del cual la actividad del pensar se vuelve sobre sí misma y retorna al interior.

Viéndolo bien, hay tres determinaciones que son características del «objeto» que se produce por medio de este procedimiento. El «yo» sobre lo cual Fichte está y seguirá hablando es 1) aquel que es "producido" a través de un acto, 2) aquel que es "producido" por un acto de pensamiento, 3) aquel que es "producido» por un acto de pensamiento de tal forma que el propio acto se vuelve o retorna sobre sí mismo ${ }^{13}$. Por consiguiente, no se está hablando aquí de un hecho o de

\footnotetext{
12 Véase VND, GA I/4, 272.

${ }^{13}$ Como escribe Fichte, uno y otro (concepto de «yo» y acto de pensar que se vuelve sobre sí mismo) se agotan el uno en el otro, i.e., son enteramente convertibles: «Beides sonach, der Begriff eines in sich zurückkehrenden Denkens, und der Begriff des Ich, erschöpfen sich gegenseitig. Das Ich ist das sich selbst Setzende und nichts weiter: das sich selbst Setzende ist das Ich, und nichts weiter. Durch den beschriebnen Act kommt nichts anderes heraus, als das Ich: und das Ich kommt durch keinen möglichen andern Act heraus, außer durch den beschriebenen.», VND, GA I/4, 272.
} 
un estado de consciencia (por ejemplo, de mi individualidad). No se está hablando de nada excepto de lo que emerge o surge en mi conciencia (o sea, de lo que se constituye para mí) en ese mismo acto de pensar. Es decir, no se está hablando del Ser del yo (no se está hablando de una supuesta existencia independiente del yo, como si el yo existiera al margen del acto de representarlo - o más bien previamente al propio acto), sino del concepto mismo que se constituye por dicha actividad de la consciencia. ${ }^{14}$

En este punto de la investigación, Fichte se adelanta a sus críticos y anticipa una posible objeción. Sin embargo, tanto la objeción que se imagina como su respuesta nos permiten fijar con mayor precisión la determinación propia del concepto del "yo" y la especificidad de lo que es representado por este concepto ${ }^{15}$. En lo fundamental, la objeción conlleva la presuposición de que yo tengo primeramente que existir como sujeto para después poder producir y protagonizar mi acto de pensar - o también que yo tengo primeramente que existir como objeto para que el acto de volver sobre sí mismo del intelecto pueda dirigirse a él o volver sobre lo que se supone pensar. Por lo tanto, lo que se presupone es la existencia independiente del yo (es decir, que el yo exista realmente y sea algo en sí mismo independientemente de que tenga o no una representación de su existencia - i.e., que el yo sea independiente de su propio acto). De tal modo que, en un caso, dicha existencia es presupuesta como condición de posibilidad del

\footnotetext{
${ }^{14}$ «...nur dasjenige, was durch das bloße Zurückgehen deines Denkens auf dich selbst zu Stande kommt, ist das Ich, von welchem ich hier rede. [...] Das Ich kommt nur durch das Zurückgehen des Denkens auf sich selbst zu Stande, sage ich: und rede dabei lediglich von demjenigen, was durch bloßes Denken zu Stande kommen kann [...] kurz, ich rede nur vom Begriffe des Ich. Von einem Seyn des Ich außer dem Begriffe, ist hier noch gar nicht die [/] Rede.», VND, GA I/4, 273.

${ }^{15} \mathrm{Y}$ nosotros aprovechamos la oportunidad para llamar la atención sobre otro aspecto de suma importancia, a saber, el que afecta a la diferencia entre lo que es libre y lo que es necesario en el acto de pensar el concepto de "yo». Un efecto, si por un lado se trata de un acto a través del cual el sujeto se descubre como activo, o sea, como habiendo actuado por su libre y espontánea voluntad (en la medida que es un acto que el sujeto podría no haber producido), por otro lado es un acto de pensar que tiene a su base un modo de actuar necesario y determinado, que sin embargo pasa desapercibido (ya sea en cuanto modo de actuar, i.e. de pensar - y, por lo tanto, como modo de actuar, i.e. de pensar determinado - ya sea en cuanto modo de actuar, i.e. de pensar necesario. Véase EE, GA I/4, 204: «Es ist hier zweierlei zu unterscheiden: der gefoderte DenkAct: dieser wird durch Freiheit vollzogen [...] - und die nothwendige Weise, wie er zu vollziehen ist: diese ist in der Natur der Intelligenz gegründet, und hängt nicht ab von der Willkühr; sie ist etwas noth wendiges, das aber nur in und bei einer freien Handlung vorkommt; etwas gefundenes, dessen Finden aber durch Freiheit bedingt ist.»
} 
acto mismo del pensar (como condición del que piensa); en el otro caso, ella es presupuesta como condición de posibilidad del objeto de ese acto (como condición de lo que puede o debe ser pensado) ${ }^{16}$.

Ahora bien, Fichte subraya que ni el yo existe independientemente de sus actos, ni yo soy una cosa-en-sí - algo que, al ser concebido, o no es más que un pensamiento o una cierta nada para mí. A continuación se pregunta: ¿para quién tiene sentido suscitar aquella objeción y sostener que hay — que tiene que haber - algo independiente del propio pensamiento y que al mismo tiempo es condición tanto del propio pensamiento como de su objeto? Sin duda que para quienes consideren evidente que tiene que haber algo independiente del propio pensar, y que por tanto contestarán: "para mí» — es decir, para su propio pensar. ${ }^{17}$ Lo que Fichte trata de enfatizar es que, cuando se presupone una existencia del yo previa al acto de pensarlo, esa existencia independiente es, a pesar de todo, pensada por alguien, puesta por alguien que se lo piensa. En otras palabras, por muy grande que sea la evidencia respecto a la existencia independiente, ella no es más que el correlato de un acto del pensar ${ }^{18}$.

Fichte no niega que dicha evidencia se imponga al pensar como algo irrecusable. Lo que subraya es que dicha «irrecusabilidad» sólo tiene lugar en el propio pensar y en la medida en que la existencia independiente del yo es pensada - o sea, sólo tiene lugar como correlato del acto por medio del cual la actividad ideal se vuelve o retorna sobre sí misma. En definitiva, si hay algo de necesario en la presuposición de la existencia independiente del yo (en la presuposición de

16 «...entweder: ich soll denk en , aber ehe ich denken kann, muß ich seyn; oder [...]: ich soll mich denken, in mich zurückgehen; aber was gedacht werden soll, auf welches zurückgegangen werden soll, muß seyn, ehe es gedacht oder darauf zurückgegangen wird.», VND, GA I/4, 273;

${ }^{17}$ Véase $W L n m-K, G A I V / 3,345$ : «Man denkt [:] ehe ich so und so es machen kann, muß ich sein. [...] oder man sagt ferner: ehe ich handeln konnte [,] mußte doch ein Object sein, auf das ich handelte. Aber was will denn dieser Einwurf sagen? wer machte denn diesen Einwurf [?] [/] Ich selbst, ich sezte mich also vorher selbst, und der ganze Einwurf ließe sich auch so ausdrücken: ich kann das Setzen des Ich nicht vornehmen, ohne ein Gesetztsein des Ich durch sich selbst anzunehmen.».

${ }^{18}$ De modo que es porque pienso en ello que puedo alguna vez presumir saber algo acerca de ello, que pueda siquiera pronunciarme acerca de ello, que pueda justamente suscitar la objeción. "Du weißt doch hoffentlich von diesem vorauszuzetzenden Daseyn nur insofern, inwiefern du es denkst; und dieses Daseyn des Ich ist sonach auch nichts mehr, als ein Gesetztseyn deiner selbst durch dich selbst.», VND, GA I/4, 274. 
algo que es y en la presuposición de eso 1) como condición para poder ser pensado y 2) como condición del propio pensar que lo piensa); dicha necesidad es algo puesto en la esfera del propio pensar- es decir, se trata de un acto necesario de la consciencia. En otras palabras, la necesidad de la que aquí se habla es una necesidad de la esfera del propio Setzen: el Setzen del Sí (o más bien el Selbstsetzen actual elevado a una consciencia de sí) implica —o sea, implica en cuanto Setzen - un otro Setzen que, por su parte, tampoco es sin presuponer un Setzen (i.e., implica el Setzen inconsciente de la existencia independiente del yo como condición del objeto del primer Setzen). De tal modo que lo que está en juego es la relación entre dos Setzungen, y nada más que eso.

Lo que Fichte sostiene para explicar el hecho de que haya para mí un pensamiento que se me impone (el pensamiento de que yo tenga que haber existido antes que - y para que - pueda pensar y ser pensado) es que en este caso estamos ante la presencia, no de un acto libre, sino de un acto necesario de la razón ${ }^{19}$. Según Fichte, además del acto que viene claramente a la consciencia en el momento en que pienso "yo», también tengo que pensar este mismo acto como habiendo sido precedido por "otro" acto de auto-posición. Simplemente, sucede que yo no tengo la clara consciencia de ser o de haber sido activo en el último caso - es decir, no tengo consciencia de ese acto 1) como acto y 2) como acto mío; lo que de inmediato se me presenta es siempre ya un hecho consumado ${ }^{20}$. Esto permite aclarar lo que ya habíamos visto con respecto a la relación entre las dos Setzungen: que no sólo contrastan entre sí por lo que respecta a su modo de ser y a su grado de distinción (la Setzung necesaria contrasta con la Setzung del acto libre por su carácter confuso) sino que también sucede que la última (en cuanto distinta) presupone la primera ${ }^{21}$. Dicho de otro modo: cuando me determino yo

${ }^{19}$ Véase $V N D, G A I / 4,274$.

${ }^{20}$ «In dem Faktum [...] liegt sonach [...] nichts mehr, als dies: du musst deinem gegenwärtigen zum deutlichen Bewusstseyn erhobenen SelbstSetzen ein anderes solche Setzen, als ohne deutliches Bewusstseyn geschehen, voraus denken, worauf das gegenwärtige sich beziehe und dadurch bedingt sey.", VND,GA I/4, 274.

${ }^{21}$ Sin embargo, no podemos perder de vista que, según Fichte, de ningún modo se puede hablar de un nexo temporal entre el primer y el segundo acto - además, Fichte insiste en que no se trata sino de un solo acto y que todo tiene lugar a la vez, (véase WLnm-K, GA IV/3, 339-340). Pero porque se trata de algo complejo por su propia naturaleza, su análisis debe detenerse en (y considerar uno por uno) cada uno de sus momentos al reconstituir dicho acto. - La Setzung consciente del yo se presenta a sí misma como necesariamente precedida (presupone necesariamente algo anterior a ella). Sin embargo, dicha anterioridad es una anterioridad puesta a partir de aquello que, para 
mismo a pensar el «yo», ya siempre me encuentro a mí mismo puesto de antemano - o sea, previamente a mí acto reflexivo (acto que también se distingue del acto inconsciente por ser intencional) — y esto sin que por eso sea consciente del acto que precede a mi acto libre de auto-posición y, por lo tanto, sin que lo reconozca como un acto mío. Si en ese momento me quiero hacer consciente de lo que pueda haber estado envuelto en ese acto necesario, tengo que abstraer el resultado de mi acto consciente y someter el acto mismo a un nuevo acto de reflexión. Es decir, tengo que hacer de mi actividad (de la actividad que ha estado a la base del hecho de consciencia producido por mí) un objeto de consideración, y concentrar allí toda mi atención.

Aquí se toca un punto decisivo. Aquello de lo que se trata cuando se habla de actividad, del pensar, del yo, etc., no tiene que ver con un actuar, un pensar o un yo meramente adjetivos con relación con una realidad independiente que les corresponde. En cierto modo, lo que hay es un universo de relaciones de dependencia en la esfera de los actos mismos. Y justo la existencia independiente del yo —el yo como realidad independiente, el yo representado como algo que existe con independencia del acto de representarlo- se nos revela como Setzung de un pensar, de una determinada actividad, de un yo. Por su parte, la actividad, el pensar, el yo son por si mismos, esto es, con independencia de todo lo demás, de todo lo que haya más allá de ellos ${ }^{22}$. Eso es lo que Fichte expresa cuando modifica la fórmula usada

dicha anterioridad, surge como algo segundo. Es la actividad libre de poner del yo que pone la existencia independiente del yo como presupuesto necesario de sí misma (i.e., que la pone como algo 1) que no tiene consciencia del poner y que 2) por eso, no le surge como puesto por ella). De tal modo que, viéndolo bien, lo que se encuentra no es de ningún modo la existencia independiente del yo, primero, y su representación después. Lo que se descubre es, de cierto modo, lo contrario. Simplemente, desde el punto de vista de su relación con la Setzung que presupone como necesaria, el sujeto no percibe su actividad en todo ello. Es decir, no tiene la consciencia de su envolvimiento en la respectiva producción. Desde luego, el sujeto no tiene la consciencia de ese acto como acto. Lo que sí tiene es siempre y solamente su resultado, o sea, lo que tiene es siempre y solamente el hecho, el producto y no la producción, aunque el sujeto no reconoce siquiera que se trate de un producto o de un resultado. Es decir, el sujeto no remite el estar dado para sí mismo de antemano a ninguna actividad, no piensa lo que pueda haber estado en su origen.

${ }^{22}$ Véase EE, GA 1/4, 196: «Ein Ding [...]: für Wenist es denn das? wird niemand, der das Wort versteht, antworten: für sich selbst; sondern es muß noch eine Intelligenz hinzugedacht werden, für welche es sey; da hingegen die Intelligenz nothwendig für sich selbst ist, was sie ist, und nichts zu ihr hinzugedacht zu werden braucht. Durch ihr Gesetztseyn, als Intelligenz, ist das, für [/] welches sie sey, schon mit gesetzt.». 
para determinar el yo: «El yo es un ponerse a sí mismo» — al añadir "para el yo» ${ }^{23}$. O como también dice: lo que está en juego no es el Ser del yo fuera del concepto, sino más bien en el concepto. De tal modo que, cuando se habla del yo, se habla de algo que consiste pura y simplemente en la representación: en la representación de la propia actividad de representar, o sea, en la representación de sí mismo o en el concepto del sí mismo.

Así, y de manera resumida, el recorrido hecho hasta aquí nos ha permitido 1) hacernos conscientes de uno mismo como esencialmente activo, 2) enfocar la especificidad de aquel modo de actuar que consiste en el volverse sobre sí misma de la actividad ideal, 3) distinguir lo que es producido como resultado y en virtud de esa actividad ( el concepto "yo») de lo que se constituye para nosotros siempre que dicha actividad no se vuelve sobre sí misma, 4) reconocer que el acto libre de autoposición presupone un acto «inconsciente», o bien pre-reflexivo - pero necesario- que está en el origen de la presuposición de la existencia independiente, y 5) reconocer que el concepto de "yo» (del yo como representación, como Setzung de sí- en cuanto «Sich selbst setzen») no depende sino de sí mismo, no implica nada que no pertenezca a la esfera del propio Setzen en cuanto tal, es decir, que pertenece a esa esfera en cuanto algo que es por sí mismo.

Adquirida la consciencia de uno mismo como esencialmente activo, el enfrentamiento del sujeto del acto libre de auto-posición con la posibilidad de que aquello que le surge como un hecho (como un hecho absoluto) sea en realidad algo puesto por si - algo puesto en un acto suyo pero del que habitualmente no tiene consciencia (y no percibe) ni en cuanto acto ni en cuanto suyo- constituye un momento decisivo, a saber, el momento en que Fichte solicita al lector que se eleve hasta el punto de vista de la filosofía transcendental.

\section{II.}

El segundo parágrafo del Versuch empieza con una revisión del itinerario seguido en el parágrafo anterior. Su reconsideración nos lleva y nos eleva, como se dice justo al inicio, hasta un punto de vista superior en el plano especulativo. Dicha ele-

\footnotetext{
${ }^{23}$ «das Ich ist ein sich selbst Setzen, [...] : für das Ich.», VND, GA I/4, 273.
} 
vación (Erhebung) tiene que ver con una más precisa comprensión del yo, tanto por lo que respecta a su peculiar actividad, como por lo que respecta sus implicaciones.

En el parágrafo primero, se sugirió al lector que pensase en sí mismo y que prestase atención al procedimiento seguido por sí mismo al representar un objeto exterior, al pensar el propio yo, etc. Para asentir a lo que me había sido requerido, tuve que volverme hacia mí mismo (se presupone, pues, que no estaba orientado hacia dicha dirección), y después hacer un esfuerzo de concentración. En el caso del pensarme a mí mismo, el esfuerzo de concentración consistió en abstraer del resultado de mí primera actividad (del yo como hecho de consciencia) y en enfocar la actividad misma, i.e., al modo de proceder al pensarse el yo. Dicho de otro modo, el acto que consiste en pensarme a mí mismo fue el objeto del segundo acto, i.e., del acto que consistió en prestarle atención - y no lo que ha resultado en virtud de él. Conviene, pues, señalar y no olvidar que lo que ha tenido lugar en ambos casos es una acción, esto es, una acción a la que se tuvo que prestar atención en un segundo momento.

Fichte prosigue su exposición diciendo que el segundo acto (el acto de prestar atención a mí acto de pensar en mí mismo) constituye el elemento subjetivo, mientras que el modo como yo tengo necesariamente que proceder para pensarme a mí mismo (aquello hacia lo que el segundo acto se dirige) constituye el elemento objetivo de la investigación desarrollada en el parágrafo anterior. Es decir, por un lado, yo no me hubiera hecho consciente de mí mismo si hubiera dirigido mi pensamiento hacia el exterior, puesto que en ese caso yo no sería para mí mismo el objeto de mi consciencia. Por otro lado, tampoco sabría de mí en cuanto principio activo sin haber prestado atención al modo como me he constituido para mí mismo.

Pero si en el primer parágrafo lo que estaba en discusión era el atender al procedimiento seguido en la representación de uno mismo o de un objeto exterior, lo que ahora se trata de considerar es más bien la propia atención (o sea, la atención que constituía el elemento subjetivo en el primer parágrafo). Por lo tanto, se trata de prestar atención a la propia atención y, en particular, se trata de prestar atención a la atención que se ha enterado de la auto-posición del yo ${ }^{24}$.

${ }^{24}$ "Jetzt aber sage ich dir: bemerke dein Bemerken deines SelbstSetzens» VND, GA I/4, 274. 
O como Fichte también dice, se trata de convertir lo que antes fuera el elemento subjetivo en objeto de una nueva investigación, someterlo a una nueva reflexión. O sea, ya no se trata de un objeto, ni siquiera de su mera representación, sino del acto que consiste en la representación de la representación. Veamos más de cerca lo que está implicado en esta operación.

El acto de pensar el yo era, en el primer parágrafo, un acto de segundo orden, o bien el elemento objetivo. O sea, era el acto que tendría que ser objeto del acto de primer orden - acto que consistía en prestar atención al modo como se había procedido al pensarse el yo, y que por lo tanto era en ese primer parágrafo el elemento subjetivo. Viéndolo bien, en el parágrafo primero lo que estaba siendo observado no era el concepto del yo; lo que entonces estaba siendo objeto del acto de prestar atención era más bien el modo como el concepto del yo estaba siendo pensado. No el qué del resultado sino el cómo de la producción, o más bien el modo de proceder al pensarse el yo- eso era el elemento objetivo.

En el segundo parágrafo, el elemento subjetivo (el acto de primer orden) es de nuevo un acto que consiste en prestar atención. Sin embargo, aquello a lo que se tiene que prestar atención y que ahora representa el elemento objetivo es, también él, un acto de prestar atención. En efecto, aunque no deje de ser un acto que consiste en prestar atención, el acto de prestar atención que ha sido considerado en el parágrafo primero no puede sino ser ahora el elemento objetivo (el acto de segundo orden), una vez que el elemento subjetivo es, en este parágrafo, el acto de prestar atención al acto mismo de prestar atención. O sea, el elemento objetivo de este parágrafo es el acto de primer orden o el elemento subjetivo del parágrafo anterior (acto que consistía en prestar atención al modo como se procede cuando se piensa el concepto del yo). De suerte que lo que había sido presupuesto en el primer parágrafo era el concepto del yo, mientras que lo que ahora es presupuesto es ya la actividad misma de pensar el yo.

Esta inflexión supone para Fichte un punto decisivo. Intentemos ver mejor sus contornos. Fichte empieza por enfocar un aspecto crucial para todo el desarrollo de la Wissenschaftslehre: el que tiene de ver con la articulación entre la consciencia del objeto - de un objeto cualquiera (es decir, sea lo que sea, incluso el propio yo) - y la auto-consciencia. Lo que Fichte señala es que al tener consciencia de un objeto - por ejemplo, de la pared — yo soy consciente de mí acto de pensar en la pared, y solamente en cuanto soy consciente de dicho acto como 
un acto mío puedo pensar en la pared. O sea, cuando represento un objeto debo al mismo tiempo ser consciente de mi acto de representarlo. Sin embargo, para que sea consciente de mi acto de pensar o representar el objeto (para que pueda tener conciencia de dicho acto en cuanto un acto mío, en cuanto un acto que, por así decirlo, me pertenece, en cuanto un acto que yo mismo realizo), tengo también que ser consciente de mí mismo ${ }^{25}$. Si yo no fuera consciente de mí mismo tampoco podría reconocer el acto de pensar en el objeto como un acto que yo mismo realizo (o sea, no podría referirlo a mí mismo). Pero que yo sea consciente de mí mismo, nos dice Fichte, conlleva necesariamente que yo distingo en mí mismo el yo que piensa del yo que es pensado, el yo que se representa a sí mismo del yo que está siendo representado, el yo que actúa, que reflexiona y que desempeña el rol de sujeto del yo que es objetivado. Según Fichte, esto tiene por fuerza que ocurrir. ¿Pero cómo es posible hacer semejante distinción? Con esto tocamos aquí un punto clave.

En este momento de la exposición, Fichte hace un triple recurrido, o más bien su digresión se desdobla en tres momentos distintos que sin embargo tienen en común el hecho de enfrentarse con el mismo argumento. Su objetivo es examinar el modelo comúnmente aceptado para explicar la consciencia y demostrar que dicho modelo no aporta comprensión alguna, sino todo lo contrario. Intentemos acompañar a Fichte y comprender su razonamiento.

Según Fichte, cuando yo digo que soy consciente de mí mismo hago una distinción en mí mismo entre el yo que es sujeto y el yo que es objeto de mi consciencia. Pero para que yo pueda distinguir el yo que es pensado del yo que se piensa - para poder establecer su relación, distinguir el uno del otro y percibir en qué consiste su diferencia- yo tengo que ser consciente de ambos. Sin embargo, yo no puedo ser consciente del yo que se piensa (es decir, de mí mismo en cuanto sujeto de mi consciencia) sin que yo mismo lo piense, i.e., sin someterlo a un nuevo acto de consciencia. Pero al pensarlo y con pensarlo, en el acto mismo, el yo que se piensa se convierte (para mí) en un objeto de consciencia. Es decir, al reflexionar sobre el yo que se piensa, ya no lo aprehendo más como sujeto sino como objeto de consciencia. Ahora bien, con esto yo me enteraría de los dos, del yo que es pensado y del yo que se piensa a sí mismo, y al ser consciente

\footnotetext{
${ }^{25}$ "Aber um deines Denkens dir bewusst zu seyn, musst du deiner selbst dir bewusst seyn.», VND, GA I/4, 275.
} 
de ambos podría por fin contraponerlos y determinarlos como momentos distintos de una misma consciencia. Simplemente, el que era sujeto no es más el sujeto; ambos son ahora objetos de mi consciencia. Lo que ha sucedido es que al reflexionar sobre el yo que se piensa me he tornado consciente de él, pero al objetivarlo he perdido el rastro del sujeto en cuanto sujeto y, con eso, a uno de los elementos que constituyen la consciencia. De modo que otro sujeto tiene necesariamente que ser puesto - aquel para el cual la consciencia misma del sujeto (y del objeto) es ahora un único objeto de consciencia. Este sujeto del nuevo acto de pensamiento es, según Fichte, consciente de la consciencia, i.e., consciente de la auto-consciencia por oposición al ser de la auto-consciencia ${ }^{26}$.

Pero ¿qué sucede si en este momento preguntamos por la consciencia que el nuevo sujeto tiene de sí mismo? En la secuencia de lo que ya hemos visto, este sujeto tendrá también que distinguirse de su objeto para que pueda ser consciente de sí mismo en cuanto sujeto. Sin embargo, al tornarse consciente de sí mismo se convierte para sí mismo en objeto de consciencia - y de nuevo tenemos que presuponer otro sujeto sin el que no habría consciencia de la auto-consciencia. Es decir, siempre necesitamos para cada consciencia objetiva de una otra consciencia, o sea, de la consciencia de la consciencia, y de nuevo de la consciencia de la consciencia de la consciencia, etc. ${ }^{27}$. Pues bien, en esta regresión infinita, uno se pregunta cuando, y si en algún momento, estaremos por fin en condiciones de poder admitir que haya efectivamente una consciencia. En términos generales, este es el problema.

Por si quedaran dudas o la argumentación no fuera convincente, Fichte revisa y retoma la discusión. Uno sólo es consciente de sí mismo —uno sólo es objeto de consciencia para sí mismo- en tanto que al mismo tiempo es también consciente de sí mismo como sujeto consciente. Y a la inversa: el que así es consciente (el que tiene consciencia de sí, el sujeto de la auto-consciencia) es al mismo tiempo un objeto para sí mismo. Pues de no serlo no se podría hablar de auto-consciencia; es decir, aquello de lo que el sujeto sería consciente no sería él mismo, sino algo diferente. Pero al hacerse consciente de sí tiene una vez más que tornarse consciente de sí en cuanto sujeto de este último acto de conscien-

${ }^{26}$ Véase $V N D, G A I / 4,275$.

${ }^{27}$ «...wir werden sonach ins unendliche fort für jedes Bewusstseyn ein neues Bewusstseyn bedürfen, dessen Object das erstere sey...», VND, GA I/4, 275. 
cia - o sea, en cuanto sujeto consciente del acto que consiste en pensarse a sí mismo (acto por medio del cual se convierte él mismo en el objeto de su consciencia). Pues si en el seno de mi auto-consciencia yo mismo soy lo que ahí es objeto de mi acto de pensamiento, tengo que distinguirme, en cuanto sujeto, de mí mismo en cuanto objeto. A falta de esto, yo no sería para mí mismo el sujeto, i.e., el que se piensa. Por lo tanto, yo tengo que aprehenderme no como lo que es pensado sino como aquel que se piensa. Pero como consecuencia de dicho acto de aprehensión yo mismo resulto objetivado (es decir, mi actuar resulta fijado), por lo que no desempeño más la función de sujeto de la consciencia sino que me encuentro en la posición opuesta: yo soy, entonces, para mí mismo, un objeto o hecho de consciencia. Al reflexionar sobre mí mismo, no me aprehendo en cuanto que actúo, en cuanto dirijo y conduzco mi pensamiento, sino en cuanto eso mismo que es representado. Al pensarme a mí mismo, lo que obtengo no es el yo en cuanto sujeto sino un yo que ha sido objetivado. Una vez más la revisión del argumento ha producido el mismo resultado que antes y confirmado la sospecha de que por esta vía no logramos explicarnos la consciencia ${ }^{28}$.

Fichte hace aún un último esfuerzo por aclarar el problema y el motivo de por qué no ha sido posible resolverlo. Dice: yo sólo puedo ser consciente de un objeto bajo la condición de que sea también consciente de mí mismo, esto es, bajo la condición de que sea consciente de mí mismo como sujeto consciente. Y si con relación a un objeto exterior yo me comprendo como sujeto de la consciencia, ya en el seno de mi auto-consciencia yo soy para mí mismo también lo que ahí es el objeto de mi consciencia. Es decir, por muy distinto que yo pueda ser para mí mismo de un mero objeto, de algún modo soy el objeto de mi autoconsciencia. En el primer caso, yo no podría ser consciente de ningún objeto exterior sin que fuera consciente de mí mismo en cuanto sujeto del acto de pensamiento por medio del cual lo represento. Yo no podría ser consciente de dicho acto en cuanto un acto que es mío sin que fuera consciente de mí mismo como aquel a quien pertenece dicho acto. Por otro lado, yo tampoco podría ser sujeto consciente de mí mismo sin ser para mí el objeto de mi consciencia. Por lo tanto, lo que era válido para el caso de la consciencia de un objeto exterior no lo es

${ }^{28}$ «Du bist dir deiner, als des Bewussten, bewusst, lediglich inwiefern du dir deiner als des Bewusstseyenden bewusst bist: aber dann ist das Bewusstseyende wieder das Bewusste, und du musst wieder des Bewusstseyenden dieses Bewussten dir bewusst werden, und so ins unendliche fort...", VND, GA I/4, 275. 
menos en el caso de la auto-consciencia: el sujeto se convierte para sí mismo en objeto, por lo que siempre hace falta pensar otro sujeto - y otro, y otro más, y así una y otra vez hasta el infinito ${ }^{29}$. El resultado de todo ello es que por este camino no logramos explicar la consciencia. Ya lo habíamos visto. Lo que se trataba era de percibir qué, cómo y por qué sucedía algo semejante- o sea, cuál era el problema ${ }^{30}$.

Sin embargo, Fichte nos afianza - por si hubiera alguna duda — que hay una consciencia ("Nun aber ist doch Bewusstseyn», VND, GA I/4, 275). Por consiguiente, la tarea es más bien la de identificar la razón de por qué hemos fracasado a la hora de explicar la consciencia — y por qué teníamos necesariamente que haber fracasado mientras persistiésemos en el error de seguir pensándola de ese modo. Si en un primer momento teníamos la tendencia de considerar que el problema consistiría justo en el procedimiento reflexivo- esto es, que hubiéramos cometido algún error en algún razonamiento-, ahora todo el recorrido de Fichte apunta en otro sentido, a saber, a que el error procedía del modo como pensábamos la relación entre el sujeto y el objeto. Por lo que desde el comienzo el problema residía en el modelo mismo adoptado para explicar cómo es posible y como se constituye para sí misma la unidad de la consciencia.

Ahora bien, a lo largo del recorrido, ¿qué es lo que siempre hemos hecho? ¿Qué es lo que nunca ha cambiado en cada nuevo intento de comprenderla? Desde luego, nunca hemos pensado la consciencia como una unidad y como un todo originario. Al pensarnos la consciencia, siempre hemos separado el sujeto del objeto (o más bien, siempre los hemos supuesto separados). Es verdad que los hemos pensado, pero siempre los hemos pensado como si estuvieran desligados,

${ }^{29}$ «... jedes Object kommt zu Bewusstseyn lediglich unter der Bedingung, daß ich auch meiner selbst des bewusstseyenden Subjects, mir bewusst sey. Dieser Satz ist unwidersprechlich. Aber in diesem SelbstBewusstseyn [...] bin ich mir selbst Object, und es gilt von dem Subjecte zu diesem Objecte abermals, was von dem vorigen galt; es wird Object und bedarf eines neuen Subjects, und sofort ins Unendliche.», VND, GA I/4, 275.

${ }^{30}$ Véase, $V N D, G A I / 4,275$. En lo fundamental, el problema es el de la regresión infinita, que resulta de pensar el sujeto y el objeto por separado con respecto a las condiciones de posibilidad de una misma y única consciencia. Fichte no omite ni disimula la dificultad. Todo lo contrario. Se enfrenta a ella una y otra vez; retomando el mismo argumento y repitiendo su análisis dos y tres veces para que quede bien claro que el modelo explicativo que viene siendo adoptado no nos permite encontrar una respuesta definitiva a la cuestión. 
y reflexionando del uno hacia el otro, los hemos considerado independientes entre sí uno del otro —así como que la consciencia resultaría de su conexión y de la posibilidad de conectarlos. Sin darnos cuenta, siempre hemos pensado la consciencia como un agregado, o sea, como algo compuesto — por así decirlo por la suma de sus partes, de tal modo que sujeto y objeto existirían previamente a la consciencia, que en última instancia (en cuanto totalidad) dependería de ellos- como si fuese una síntesis post factum ${ }^{31}$.

Ahora bien, la concepción de Fichte para explicar la consciencia sostiene todo lo contrario. Por un lado, presupone que la totalidad, (i.e., la consciencia misma) es primera y no algo obtenido como resultado. O sea, presupone que sólo porque ya hay consciencia es posible abstraer y reflexionar a la vez sobre sujeto y objeto (que sólo es posible descomponerla en —y analizar sus- "partes» porque la consciencia es - por decirlo con Kant- una totalidad originariamente sintética, una unidad que no resulta de la colección de lo diverso pero que tampoco es posible como algo simple, sino que consiste en un complejo sistema de relaciones. La consciencia conlleva en sí misma una multiplicidad de elementos, los cuales están recíprocamente relacionados, de tal modo que — por así decirlo- se entretejen mutuamente. La consciencia sólo es posible como multiplicidad y lo que hace posible dicha multiplicidad en cuanto multiplicidad es el hecho de que cada uno de sus elementos no puede ser sin todos los demás, o sea, el hecho de que cada uno se hace y es a la vez condición de todos los demás - el hecho de que cada uno presupone (y es a la vez presupuesto por) todos los demás. Por otro lado, su concepción de la consciencia conlleva la unidad absoluta de todos sus momentos- de tal modo que sujeto y objeto no están desligados (el uno del otro) y cada uno de ellos encerrado en su propia esfera, apartados (el uno del otro) como si fueran elementos extrínsecos e independientes, sino que están en una relación recíproca. Igualmente, tampoco sujeto y objeto son elementos

${ }^{31}$ Esa es, según Fichte, la razón por la cual, por lo menos hasta ahora, no hemos logrado comprender la consciencia. Es decir, la imposibilidad de comprender la consciencia como un todo se debía, por un lado, a la falsa comprensión que teníamos de la constitución de la totalidad y de la relación entre el todo y sus elementos (sujeto y objeto) y, por otro lado, al modo como mal comprendíamos la relación entre ellos; y en esto reside el problema, a saber, no en una imposibilidad de comprensión, sino que en una falsa comprensión de la constitución de la totalidad y en una no comprensión de la relación entre sujeto y objeto. Véase, VND, GA I/4, 275. 
absolutamente simples, sino que en virtud de su naturaleza todas las determinaciones de la consciencia son complejas, es decir, ellas mismas sintéticas.

Si hubiera una tal consciencia, es decir, si lográsemos encontrar una consciencia en la que el sujeto y el objeto constituyesen una unidad (de consciencia) indisoluble y originariamente sintética, ahí tendríamos el tipo de consciencia que necesitamos para poder explicar la consciencia. O sea, una consciencia que se pone por sí misma y que en el mismo acto pone en sí y para sí misma la oposición entre sujeto y objeto- una consciencia que tenga como condición de su posibilidad, no la posición absoluta de cada uno de sus momentos, aislados y desligados el uno del otro, sino la posición de la totalidad misma y, en su seno, la escisión por la cual se constituyen para sí misma ya sea la consciencia de sí misma, ya sea la consciencia de todo lo demás, i.e., la consciencia de su diferencia. Una consciencia en la cual la unidad sujeto-objeto sea puesta con, por y para ella conllevaría que ninguna de las "partes» del todo fuese previa a la otra y, desde luego, que ninguna fuese previa al todo, de tal modo que solamente con la simultaneidad de todas las «partes» resultaría puesta la totalidad a la que pertenecen y de la cual dependen. La escisión sería entonces una escisión que tendría lugar en el seno de la totalidad, es decir, una vez y solamente puesta la totalidad. Por lo que lo primero siempre sería la unidad de la consciencia. La consciencia sería siempre ya algo para sí misma, es decir, sería siempre ya en relación consigo misma, y la autoconsciencia sería la condición necesaria de la consciencia. Por lo tanto, no es verdad que sea imposible explicar la consciencia. El problema estaba en el modelo, que no era adecuado para comprenderla. De modo que no hay que hacer depender la explicación de la consciencia de lo que dicho modelo propone sino encontrar el modelo que nos permita explicar la consciencia ${ }^{32}$.

Teniendo esto en mente (y si es cierto que es indudable el hecho de que pensábamos, en qué pensábamos y cómo lo estábamos haciendo), Fichte nos pregunta cómo hemos logrado obtener la consciencia del pensar mismo, y responde que jamás podríamos contestar de otro modo que no fuese «lo supe inmediatamente». Pero ¿por qué razón es necesario que la respuesta fuera esa? Porque no es posible para nosotros pensar nuestro pensar sin que al hacerlo no tengamos consciencia de ello. Porque la consciencia de mi propio pensar — tendríamos que

${ }^{32}$ Véase VND, GA I/4, 275. 
haber dicho — no es un accidente o algo que pudiera faltar o no acompañar a mi pensamiento en el momento en que pienso sea lo que sea (en un objeto exterior o en mi mismo). La consciencia de mi propio pensar no es algo superpuesto a mi propio pensar; es decir, no es algo que se le añade, no es algo puesto además de él y conectado con el pensar de una manera externa. No hace falta que reflexione sobre mi propio pensar para ser consciente del acto que yo mismo realizo. Por el contrario, la consciencia que tengo de mi pensar es inseparable de la actividad, es decir, del pensar mismo. No tengo que reflexionar sobre mi propio pensar para saber lo que estoy haciendo y que lo estoy haciendo — no sólo soy inmediatamente consciente de dicha actividad, sino además soy consciente de mí mismo en cuanto pienso y todo ello no en diferentes momentos sino simultáneamente. Mi pensar y la consciencia de mi pensar son para mí al mismo tiempo idénticos. En eso consiste, según Fichte, la auto-consciencia, como consciencia en la que el elemento subjetivo y el elemento objetivo están inmediatamente uni$\operatorname{dos}^{33}$ - el tipo de consciencia que antes buscábamos y que no lográbamos encontrar mientras seguíamos separando sujeto y objeto y pensándolos como previos a la consciencia (consciencia cuya unidad inmediata no lográbamos encontrar por medio del modelo reflexivo).

Ahora bien, si son uno y lo mismo, mientras pienso en el acto que es mi pensar, la consciencia de mi acto no emerge después, ya que en el acto mismo y con el acto mismo - es decir, en el exacto momento en que yo pienso, en ese preciso momento soy 1) consciente del acto como un acto que es mío y 2) consciente de mí mismo en cuanto que soy yo quien lo realizo. Mientras pienso en mi acto de pensarme a mí mismo, la consciencia de mí mismo en cuanto sujeto activo no se añade al acto como algo enteramente distinto, sino que la consciencia de mi acto de pensar tiene lugar con el acto y en el acto mismo de pensar. Mientras pienso en mi acto de pensar, mi consciencia no se conecta con el acto como si fuera algo absolutamente diferente y yuxtapuesto al acto, sino que es inseparable de él y, por lo tanto, constituye una unidad indisoluble con el acto mismo. No sucede primero el acto y después, como si viniera detrás, su consciencia. Igual que la consciencia del acto no se sigue del acto como su consecuencia. Es decir,

${ }^{33}$ «Das Bewusstseyn meines Denkens ist meinem Denken nicht etwa ein zufälliges, erst hinterher dazu gesetztes, und damit verknüpftes, sondern es ist von ihm unabtrennlich [...] Das Bewusstseyn unsers eignen Denkens ist dieses Bewusstseyn [...] ein Bewusstseyn, in welchem das Subjective und Objective unmittelbar vereignit ist.» VND, GA I/4, 276. 
en mi auto-consciencia, ni la consciencia de mi propio pensar es un resultado del acto ni el acto es representado por la consciencia. En ella —en mi auto-consciencia-, consciencia (del acto) y (mi propio) acto de pensar son indisociables - ella es la consciencia de mi propio pensar y en mi propio acto de pensar yo soy inmediatamente consciente de mí mismo ${ }^{34}$.

Por lo tanto, sí se da una auto-consciencia inmediata: la consciencia de nuestro pensar (la consciencia que el pensar tiene de sí mismo); en el acto mismo de pensarse, uno se hace a la vez consciente de sí mismo. Pero ¿cómo se representa uno la consciencia inmediata de su propio pensar? Según Fichte, de una sola manera. Todo depende del reconocimiento de que la actividad por la cual el yo se piensa o hace consciente de un objeto cualquiera está simultáneamente dirigida a si misma ${ }^{35}$. Si recordamos lo que ya hemos dicho con respecto al volverse sobre sí misma de la actividad ideal — que sin ella no se constituye el yo y que solamente el yo se constituye a través de ella-y tampoco olvidamos que, al ser consciente de algo, el yo no puede sino captar-se a sí mismo en cuanto activo, entonces podremos percibir que dicha actividad del yo se desdobla o se despliega, y que el acto por el cual el yo se entera de cualquier objeto presupone - $\mathrm{O}$ más bien conlleva- el acto a través del cual se constituye la auto-consciencia. Es decir, la consciencia inmediata de mi pensar no es sino la consciencia de mí mismo en cuanto activo. Teniendo en cuenta que el yo sólo se constituye para sí mismo con el volverse sobre sí misma de la actividad ideal, dicha actividad siempre tiene ya lugar aunque de un modo inconsciente. La consciencia presupone como condición necesaria de su posibilidad la autoconsciencia y esta última reposa sobre la consciencia pre-reflexiva de mi acto de pensar. Independientemente de lo que piense y de la dirección en la que actúe, yo no podría hacerme consciente del objeto de mí pensar si no fuera inmediatamente consciente del pensar en cuanto tal - o sea, si no fuera inmediatamente consciente de mí mismo en cuanto activo. Dicha consciencia inmediata consiste en que lo subjetivo y lo objetivo son inmediata y absolutamente uno en esa consciencia de sí mismo; y a pesar de que no sea consciente de dicha actividad (es decir, de qué actúo y de cómo actúo en ese caso), si la consciencia es comprensible, entonces es necesa-

34 «Du warst sonach in deinem Denken deiner selbst dir bewusst, und dieses SelbstBewusstseyn eben war jenes unmittelbare Bewusstseyn deines Denkens», VND, GA I/4, 276.

${ }^{35}$ Véase VND, GA I/4, 276. «... deine innere Thätigkeit, die auf etwas außer ihr (auf das Object des Denkens,) geht, geht zugleich in sich selbst, und auf sich selbst.». 
rio presuponer, según Fichte, para toda consciencia posible, un tipo de consciencia donde lo subjetivo y lo objetivo están inseparablemente unidos ${ }^{36}$.

Según Fichte, sólo este tipo de consciencia puede constituir para nosotros un primer principio, es decir, un tipo de consciencia que no es dependiente ni derivado. Sólo esta auto-consciencia es inmediata, incondicionada, absolutamente posible y simplemente necesaria. Toda otra consciencia (ya sea la consciencia de objetos exteriores, ya sea la auto-consciencia reflexiva) sólo es posible por medio de la primera; es decir, depende de ella y es condicionada por ella, está conectada con ella y mediada por ella. Sin que estuviese constituida la auto-consciencia, nada de lo que realmente existe podría ser objeto de consciencia (o sea, no sabríamos nada sobre su existencia o no existencia - porque dicha existencia o no existencia no sería nada para nosotros sin que fuéramos conscientes de nosotros mismos, i.e., sin que estuviera inmediatamente constituida en nosotros una instancia de auto-consciencia). Por consiguiente, nada podría ser pensado o representado porque es en ella, con ella y por ella que se constituye todo lo que pueda ser objeto posible de una experiencia cualquiera.

Pues bien, Fichte denomina intuición a una tal consciencia inmediata o prereflexiva ${ }^{37}$. Lo que queda por determinar es en qué consiste más precisamente dicha intuición. Según Fichte, la consciencia inmediata de sí mismo es la intuición del yo, y dicha intuición es un acto. Pero ¿qué tipo de acto? Por un lado, es un acto en el cual y con el cual se constituye todo lo que puede ser objeto posible de consciencia (ya sea un objeto exterior, ya sea el yo mismo). Pero si no fuese más que un acto de poner algo objetivo, dice Fichte, nos veríamos envueltos en la misma dificultad que antes. Es decir, a pesar de haber un objeto, no lograría-

${ }^{36}$ «Also das SelbstBewusstseyn ist unmittelbar; in ihm ist Subjectives und Objectives unzertrennlich vereinigt und absolut Eins [...] Alles mögliche Bewusstseyn, als Objectives eines Subjects, setzt ein unmittelbares Bewusstseyn, in welchem Subjectives und Objectives schlechthin Eins seyen, voraus; und außerdem ist das Bewusstseyn schlechthin unbegreiflich.», VND, GA I/4, 276.

${ }^{37}$ "Ein solches unmittelbares Bewusstseyn heißt mit dem wissenschaftlichen Ausdrucke eine Anschauung», VND, GA I/4, 276; «Dieses unmittelbare Bewusstseyn ist die so eben beschriebene Anschauung des Ich; in ihr setzt das Ich sich selbst nothwendig, und ist sonach das Subjective und $\mathrm{Ob}[/]$ jective in Einem. Alles andere Bewusstseyn wird an dieses angeknüpft und durch dasselbe vermittelt; wird lediglich durch dir Verknüpfung damit zu einem Bewusstseyn: dieses allein ist durch nichts vermittelt oder bedingt; es ist absolut möglich und schlechthin nothwendig, wenn irgend ein anderes Bewusstseyn statt finden soll.», VND, GA I/4, 277. 
mos explicarnos la consciencia sin que también fuese puesto su elemento subjetivo, i.e., la consciencia de la consciencia. Si esto es cierto, es necesario que además de ponerse como objeto, el yo se ponga en ese mismo instante como sujeto del acto de consciencia, es decir, como consciencia de la consciencia - en cuanto consciencia inmediata del acto de poner él mismo. Por lo tanto, la intuición de la que nos habla Fichte no es un mero acto de poner algo objetivo, sino que es un acto en el cual el yo se pone a sí mismo en cuanto consciente de su rol activo- - un acto en el cual el yo no es para sí mismo algo meramente puesto sino también el sujeto del acto mismo. Es decir, dicha intuición es un acto de autoposición y, en él, el yo se pone en cuanto puesto por sí mismo y en cuanto el acto de ponerse él mismo - o sea, en cuanto sujeto-objeto, en cuanto el que aprehende y lo que es aprehendido, es decir, en cuanto inmediatamente consciente de sí mismo. De modo que dicha consciencia inmediata consiste en que el que está en el origen de lo que es puesto como objeto de consciencia sabe necesariamente de sí como sujeto de ese mismo acto, i.e., en cuanto es para sí mismo el que pone, lo que es puesto y el acto de ponerse mismo. En suma, en esta intuición, el yo no es un simple acto de poner. En esta intuición, el yo tampoco es algo simplemente puesto (si fuese un simple acto de poner, el yo no lograría ser algo para sí mismo; si fuese simplemente puesto, el yo siquiera sería un yo, sino más bien algo meramente objetivo). Esta intuición consiste, pues, en un acto de auto-posición. Es decir, en esta intuición, el yo es el acto de intuir y él mismo es lo que es intuido- él mismo es para sí mismo la unidad sujeto-objeto; él mismo es esta intuición, comprendida en dos sentidos: en cuanto forma del acto y su contenido ${ }^{38}$.

Veámoslo con más detenimiento. ¿Cuál es el contenido de dicha intuición? Desde luego, el contenido de dicha intuición no pude ser un contenido sensible. La intuición no tiene por objeto ni una realidad exterior ni una existencia independiente que sea perceptible. El contenido de esta intuición es un acto de auto-posición: el ponerse del yo por sí mismo y para sí mismo. El contenido de esta intuición es una actividad en la cual lo que es puesto es él mismo, el ser para sí mismo del que se pone por sí mismo. Por lo que este acto sólo puede ser comprendido como un ser en tanto que el último es un «ser-intuido», es decir, un

\footnotetext{
38 «Die Anschauung, von welcher hier die Rede ist, ist ein sich Setzenals setzend, [...] keineswegs aber etwa ein bloßes Setzen ", VND, GA I/4, 276.
} 
intuirse a sí mismo, un ser para sí mismo la intuición misma de sí mismo ${ }^{39}$. El contenido de dicha intuición es, pues, una auto-relación, o sea, una acción no un Ser, sino el ser para sí del que sabe de sí en cuanto activo. Por lo tanto, la realidad en esta intuición (el Ser del yo) no puede ser más que un Ser ideal («ein ideales Seyn») — es decir, el Ser del yo es, en esta intuición, el ser de la auto-consciencia, el «seyn» en el «Selbstbewusst s e y n», y nunca una realidad o un ser estrictamente objetivo.

En esta intuición — nos dice Fichte- ni el yo existe con independencia de que sea pensado e intuido (el Yo no es una cosa-en-sí), ni existe previamente en cuanto algo que piensa e intuye en general, con independencia de que haya algo que sea pensado e intuido - es decir, independientemente de que haya consciencia ${ }^{40}$. Pero esto no es todo. Si la consciencia depende de la - y es condicionada por la auto-consciencia, la razón por la cual uno no puede presuponer la existencia del yo como previa a la consciencia es, según Fichte, porque eso sería invertir la relación de dependencia. Es decir, sería hacer de la auto-consciencia lo condicionado - sería hacer depender la primera (la condición) de un yo que existiría sin que fuese intuido o pensado (por una consciencia). Pero eso es una contradicción ${ }^{41}$. Puesto que el actuar del yo consiste en intuirse y pensarse como relación (en cuanto sujeto y objeto de la intuición en la intuición misma), el yo es al mismo tiempo el que constituye la unidad sujeto-objeto y para quien (y por el cual) es puesta, en el seno de una misma consciencia, su escisión en cuanto condición de posibilidad de la distinción entre actividad y concepto. Por lo que la oposición no es entre la consciencia y algo independiente de la consciencia; la oposición es interna a la propia consciencia.

En esta intuición, el acto que el yo se atribuye a sí mismo consiste en hacerse presente para sí mismo en cuanto unidad sujeto-objeto al mismo tiempo que

39 «Nun ist hier von keinem andern Seyn des Ich die Rede, als von dem in der beschriebenen SelbstAnschauung; oder, noch strenger ausgedrückt, von dem Seyn dieser Anschauung selbst. Ich bin diese Anschauung und schlechthin nichts weiter, und diese Anschuung selbst ist Ich.», VND, GA I/4, 277.

${ }^{40}$ «Es soll durch dieses sich selbst Setzen nicht etwa eine Existenz des Ich, als eines unabhängig vom Bewusstseyn bestehenden Dinges an sich, hervorgebracht werden, [...] Eben so wenig wird dieser Anschauung eine vom Bewusstseyn unabhängige Existenz des Ich, als (anschauenden) Dinges vorausgesetzt...», VND, GA I/4, 277.

${ }^{41}$ Véase $V N D, G A I / 4,277$. 
todo lo demás (en cuanto algo meramente objetivo) es igualmente puesto por él y se le presenta. En esta intuición, el yo es al mismo tiempo el actuar y el ser para sí mismo, el testigo de dicha actividad de la consciencia. En ella el intelecto se intuye a sí mismo en cuanto actuar de la razón misma y se diferencia en cuanto activo de un mero objeto puesto/pensado por dicho acto de inteligencia. En esto consiste la especificidad de la intuición de la que nos habla Fichte. En contraposición con cualquier otro tipo de intuición hay que designar a dicha intuición, dice Fichte, «intuición intelectual» para no confundirla con la intuición sensi$\mathrm{ble}^{42}$.

\section{III.}

El recorrido hecho hasta aquí nos ha permitido comprender que somos activos tanto al representar un supuesto objeto exterior como en el caso de representarnos a nosotros mismos. Ahora se trata más bien de prestar atención a un aspecto singular de la representación de nuestra propia actividad ${ }^{43}$. ¿Qué está envuelto en el acto de representarse en cuanto activo? ¿Qué es lo que sucede en nosotros mismos al hacernos conscientes de nuestra actividad? ¿Y cómo es eso posible - cómo logramos comprender en qué consiste y cómo se constituye la consciencia de ser activo?

Según Fichte, el entendimiento representa la actividad como un movimiento de transición que conlleva el arrancarse o desprenderse (sich losreissen) de algo previo y opuesto al acto mismo - por lo tanto, el arrancarse o desprenderse de un estado que es puesto en oposición a la actividad, algo que el pensar contrapone a la actividad misma para pensar en qué consiste la determinación propia

${ }^{42}$ «Also - die Intelligenz schaut sich selbst an, bloß als Intelligenz oder als reine Intelligenz, und in dieser SelbstAnschauung eben besteht ihr Wesen. Diese Anschauung wird sonach mit Recht, falls es etwa noch eine andere Art der Anschauung geben sollte, zum Unterschiede von der letztern intellectuel 1 e Anschauung gennant.», VND, GA I/4, 277-278; "Die Intelligenz, als solche, sieht sich selbst zu; und dieses sich selbst Sehen, geht unmittelbar auf alles, was sie ist, und in dieser un mittelbaren Vereinigung des Seyns, und des Sehens, besteht die Natur der Intelligenz. Was in ihr ist, und was sie überhaupt ist, ist sie für sich selbst; und nur in wie fern sie es für sich selbst ist, ist sie es, als Intelligenz.»", EE, GA I/4, 196.

43 «Du fandest im Vorstellen eines Objects, oder deiner selbst dich thätig. Bemerke nochmals recht inning, was bei dieser Vorstellung der Thätigkeit in dir vorkam.», VND, GA I/4, 279. 
de dicha actividad. Según Fichte, actividad supone agilidad, y se trata justamente de prestar atención a la intuición de esta agilidad. Dicha agilidad no puede sino ser intuida como un proceso en el cual una determinada fuerza (Kraft) se desprende del estado de reposo (Ruhe) — es decir, se sustrae a un estado en que dicha fuerza estaba detenida o retenida (y que justo por estar detenida no pude ser considerada una fuerza activa) ${ }^{44}$.

Lo contrapuesto a la actividad es un estado de reposo; el pensar no logra representar dicha actividad sin contraponerla a un estado de reposo. Por lo tanto, dicho acto de contraponer un estado de reposo a una actividad es un acto necesario del pensamiento. Una actividad es incomprensible si al mismo tiempo no se piensa su contrario; así como no es posible comprender en qué consiste un estado de reposo sino en oposición a una determinada actividad ${ }^{45}$. El concepto de actividad no sería representable por sí sólo sin que hubiera una intuición de dicha actividad y con independencia de que dicha actividad sea pensada en relación con lo que se distingue. Que ambos se hagan representables depende de que tanto la actividad como el estado de reposo sean diferenciables, y que sean diferenciados depende de que sean pensados en conjunto, puestos en relación de oposición. Pero ¿cómo es posible reconocerlo en lo que ya hemos visto y observar el modo como se manifiesta en nosotros mismos?

Fichte nos había pedido pensar en la pared, en la ventana, etc. Lo hemos hecho, hemos representado estos mismos objetos y una vez hecho eso (una vez

44 «Thätigkeit ist Agilität, innere Bewegung; der Geist reisst sich selbst über absolut entgegengesetzte hinweg [...] — Aber diese Agilität lässt sich nicht anders anschauen, und wird nicht anders angeschaut, denn als ein Losreissen der thät i gen Kraft von einer Ruhe...», VND, GA I/4, 279.

45 «...man findet sich thätig, nur inwiefern man dieser Thätigkeit eine Ruhe (ein Anhalten und Fixirtseyn der innern Kraft) entgegensetzt. (Der Satz [...] ist auch umgekehrt wahr: man wird sich einer Ruhe nicht bewusst, ohne eine Thätigkeit zu setzen. Thätigkeit ist nichts ohne Ruhe und umgekehrt. Ja, der Satz ist allgemein wahr [...] Alle Bestimmung, was es nur sey, das bestimmt werde, geschiet durch Gegensatz. [)]», VND, GA I/4, 279; «Also nur durch Gegensatz war ich vermögend, mir meiner Thätigkeit klar bewust zu werden, und eine Anschauung derselben zu bekommen [...] Nur durch Gegensatz ist ein bestimmtes klares Bewustsein möglich.», WLnm - K, GA $I V / 3,348$. Con todo esto, Fichte nos dice que no presume hacer que algo incomprensible se vuelva inteligible, sino llamar nuestra atención para algo que, según él, todos podemos observar en nosotros mismos (algo que se encuentra necesariamente presente en cada uno de nosotros si sólo estamos atentos): la intuición que corresponde al concepto y que acompaña necesariamente su representación y, por otro lado, la determinación por oposición. 
representados y producidos sus conceptos) nos hemos quedado fijados en ellos, inmóviles, detenidos en su contemplación. Inmediatamente después Fichte nos ha dicho que pensásemos en nosotros mismos y que prestásemos atención a lo que estaba sucediendo. Es decir, que nos pensásemos a nosotros mismos y que además nos hiciésemos conscientes de lo que estábamos haciendo y de cómo lo estábamos haciendo (que nos enterásemos de que habíamos sido activos y de cómo habíamos procedido para producir la representación de nosotros mismos). Por consiguiente, la tarea es doble: pensarse a sí mismo y hacerse consciente de lo que está implicado en ese procedimiento (i.e., enterarse de que el pensarnos a nosotros mismos conlleva algo semejante a un acto de producción).

Aquí hay varios aspectos que merecen ser señalados. Desde luego, el movimiento de transición desde el pensar en la pared al pensar en la ventana consiste en algo muy diferente, cuanto a su procedimiento, de lo que está implicado en el movimiento de transición desde el pensar un objeto exterior cualquiera hacia el pensarme a mí mismo. Es decir, para pensarme a mí mismo yo tengo que volverme hacia mí mismo desde el exterior; al pensarme a mí mismo he procedido de aquel modo especifico que consiste en el volverse sobre sí misma de la actividad del pensar - procedimiento que, como hemos visto, no produce sino el concepto del yo. De la misma manera como había sucedido al pensar un objeto exterior, si ahora me quiero enterar de que he sido activo tengo que desviar mi atención de lo representado (i.e., de lo que yo mismo he pensado) y concentrarme en el procedimiento (i.e., en el acto mismo de producirlo).

Ahora bien, al igual que el acto de pensar en la pared, una vez que haya pensado en mí mismo me quedo fijado en el yo objetivado, inmóvil, detenido en su observación. Por lo tanto, para enterarme de qué y de cómo he actuado, tengo que sustraerme al estado de reposo que corresponde a la determinidad de mi consciencia y atender a lo que pueda haber estado en su origen. Dicho acto de desprendimiento es el movimiento de transición o más bien la agilidad de que nos habla Fichte. Al realizarlo, me entero de que soy activo porque soy yo quien por un acto libre se decide abstraer del yo (en cuanto hecho de consciencia ya producido al haberme pensado a mí mismo) y atender al acto por el cual el yo se ha constituido. O sea, si soy yo el que decide prestar atención al modo como yo mismo había procedido, en ese momento yo mismo tengo que determinar mi pensar de un modo distinto. Dicho acto de auto-determinación consiste en sustraer mi pensamiento del estado de reposo previo y determinar como «objeto» 
de mí pensar, no el concepto del yo sino el procedimiento que me ha permitido obtenerlo.

Según Fichte, hay por lo menos dos condiciones necesarias para que yo me pueda hacer consciente de mí mismo en cuanto activo. Por un lado, yo me entero de que soy activo al hacerme consciente de este acto de desprendimiento (el movimiento se produce desde el estado de reposo que corresponde a la determinidad de mi pensamiento). Por otro lado, yo me hago consciente de que soy activo si y cuando la determinidad de mi consciencia ha cambiado porque yo lo he decidido ${ }^{46}$. Por lo tanto, yo me entero de que soy activo en tanto que contrapongo mi actividad al estado de reposo en el que la fuerza activa de mí pensar estaba detenida. Abstraer, enfocar, prestar atención, todos estos son actos míos, son actos que yo mismo realizo. Todos estos actos presuponen un estado de reposo y dispersión previo en el que mi pensar estaba atrapado y, por decirlo así, disuelto, al igual que todos ellos conllevan el mencionado movimiento de transición hacia algo que ya no es más un estado de consciencia sino el actuar (el «seren-acto») mismo del pensar - es decir, el pensamiento en acción (comprendido en oposición al estado de reposo, i.e., en oposición al estado de contemplación en que mi pensar estaba retenido). Por lo tanto, la consciencia de uno mismo en cuanto activo depende de la respectiva intuición. La actividad o agilidad del pensar - no el objeto ni el hecho (no el estado de reposo ni la determinidad de la consciencia), sino el acto que consiste en el movimiento por medio del cual el pensar se determina a sí mismo al desprenderse de ellos — eso es lo que ahí es intuido. Prestemos una vez más nuestra atención a esta intuición.

Nos pregunta Fichte: ¿cuál es la determinidad que inmediatamente precede a mi actividad de pensarme a mí mismo? Dicho de otro modo: ¿qué es lo que estaba inmediatamente conectado con mi actividad de modo que yo no podría enterarme de ella sin que al mismo tiempo no fuese consciente de eso? De acuer-

${ }^{46}$ «Du dachtest meiner Aufforderung gemäß deinen Tisch, deine Wand, u.s.w. und nachdem du thätig die Gedankden dieser Gegenstände in dir hervorgebracht hat[/]test, warst du nun in ruhiger fixirter Contemplation derselben begriffen [...] Ich sagte dir: jetzt denke dich, und bemerke, daß dieses Denken ein Thun ist. Du musstest, um das verlangte zu vollziehen, dich losreissen, von jener Ruhe der Contemplation, von jener Bestimmtheit deines Denkens, und dasselbe anders bestimmen; und nun inwiefern du dieses Losreissen und dieses Abändern der Bestimmtheit bemerktest, bemerktest du dich als thätig.", VND, GA I/4, 279. 
do con lo que ya hemos visto, eso tendría que ser un estado de reposo - el estado de reposo en que mi pensar estaba atrapado y del que se desprende en tanto que nuevamente se vuelve activo. Aquí nos encontramos con un punto decisivo. El estado de reposo previo al pensarme a mí mismo (la determinidad de mi consciencia previa al desprendimiento) es un concepto. Pero ¿qué concepto? A lo mejor, uno tendría la inclinación a juzgar que dicho concepto sería el del objeto correspondiente al acto previo del pensar. Por ejemplo, el concepto de la pared o de la ventana, ya que esto era lo que contemplábamos antes de que se nos dijera que nos pensáramos a nosotros mismos. Eso parece ser el estado de reposo previo al acto de pensarse a sí mismo, el estado de reposo desde el cual uno se desprende para pensarse a sí mismo. Ahora bien, esto no es el caso. Entre dicho estado de reposo del pensar correspondiente al concepto de cualquier objeto exterior y el acto libre que consiste en pensarse a sí mismo hay algo —o más bien, ha sucedido algo- que ha pasado desapercibido, algo que se ha constituido sin que tuviésemos consciencia explicita de qué y de cómo se ha producido.

Cuando se dice "piénsate a ti mismo», obtengo un nuevo objeto para mi pensamiento, otra determinidad, otro concepto. Este concepto que es el concepto de yo es el estado de reposo del que mi pensar se desprende en la medida en que se vuelve activo (es decir, en tanto que yo me determino a pensarme a mí mismo). Pero ¿cómo se comprende que dicho concepto sea previo al acto que se supone tendría todavía que producirlo? En el caso anterior (cuando se trataba de pensar un objeto exterior), ¿no era el concepto el estado de reposo y la determinidad de mi pensamiento en que me quedaba absorto después de representarlo? Entonces ¿cómo se explica que en este caso el concepto del yo sea previo, es decir, sea el estado de reposo y el punto mismo de partida para mí acto de pensarlo?

Fichte señala que antes de pensarme a mí mismo, mi pensar ya estaba determinado y mi actuar ya estaba direccionado. Pero ¿cómo y por qué? Justamente, por la comprensión de lo que tendría que hacer, a saber, pensarme a mí mismo. La instrucción "piénsate a ti mismo" no está para mí desprovista de sentido. Al decirse "piénsate a ti mismo», inmediatamente obtengo un objeto para mi pensar y una determinada dirección para mi actividad. Luego sé inmediatamente cómo proceder. Lo que yo no sabía —y, según Fichte, tampoco tendría que saberlo- es que el concepto del yo no se constituye sino en el acto del pensar que 
consiste en volverse sobre sí mismo ${ }^{47}$. Pero ¿cómo podría yo saber cómo proceder si no poseyese de antemano alguna noción de lo que tendría que hacer y del modo como tendría que hacerlo? ¿Cómo se explica que supiese corresponder a lo que me es pedido? ¿Podría yo saber lo que tendría que hacer — podría yo saber en qué dirección actuar y cómo proceder si en el exacto momento en que se dijo "piénsate a ti mismo" yo no lo hubiera comprendido? Por lo tanto, cuando se me dice "piénsate a ti mismo", yo sé hacia donde debo dirigirme. En última instancia, yo comprendo lo que se me dice. Mientras se me diga "piénsate a ti mismo", es posible que yo no sepa explicar cómo he obtenido el concepto, y sin embargo no dejo de comprender lo que tengo necesariamente que hacer para corresponder a lo que se me pide.

Lo que sucede es que al comprender el "piénsate a ti mismo» he hecho algo, he actuado de una determinada forma e inmediatamente me he vuelto sobre mí mismo desde el exterior, pero lo he hecho sin que me dice cuenta de lo que estaba haciendo y sin que lo haya comprendido en cuanto acto mismo. En este volverse sobre sí mismo consiste el procedimiento que está a la base del concepto del yo y de este modo se constituye el concepto mismo ${ }^{48}$. El concepto del yo se origina con ese mismo acto, pero sin percatarme de ese acto en cuanto acto - el acto mismo no es intuido-, ya que sólo me percato del concepto (que es el resultado inmediato de dicho acto) en cuanto que es pensado o comprendido y, por lo tanto, fijado y detenido. El concepto del yo es el resultado del acto de volverme hacia mí mismo. Ahora bien, este acto no es comprendido de inmediato como un acto, sino más bien como un estado de reposo, i.e., la determinidad correspondiente al concepto ya constituido ${ }^{49}$.

47 «Ich sagte dir: denke dich selbst [...] und du verstandest mich ohne weiters. Du wussest sonach, was das heiße: Ich. Aber du brauchtest nicht zu wissen, und wussest meiner Vorasusetzung nach nicht, daß dieser Gedanke durch ein Zurückgehen der Thätigkeit in sich selbst zu Stande komme, sondern solltest dies erst lernen.», VND, GA I/4, 279-280.

${ }^{48}$ "Nun aber ist das Ich, laut obigem nichts anders, als ein in sich selbst zurückgehendes Handeln; und ein in sich selbst zurückgehendes Handeln ist das Ich.», VND, GA I/4, 280.

${ }^{49}$ «du fandest, indem du den Ausdruck: Ich, verstandest, dich, d.h. dein Ha ndeln als Intelligenz, bestimmt auf eine gewisse Weise; jedoch ohne das bestimmte gerade, al s ein Handeln, zu erkennen. Du erkanntest es nur als Bestimmtheit, oder Ruhe, ohne eigentlich zu wissen, noch zu untersuchen, woher jene Bestimmtheit deines Bewusstseyns komme...", VND, GA I/4, 280. 
Dicha determinidad se ha constituido al volverme sobre mí mismo - movimiento en el que consiste el pensarse del yo; el concepto del yo se constituye a través de ese movimiento de volverme hacia mí mismo. Por un lado, la determinidad de mi pensar desde la cual me desprendo para pensarme a mí mismo ya ha resultado de que haya pensado en algo, es decir, de que haya actuado de un modo determinado. Sin embargo, en ese momento yo no me percato de esa actividad en cuanto actividad. Al estar determinado de mí pensar no le acompaña la consciencia del modo como ese estado ha sido obtenido. Es decir, fuese lo que fuese lo que se encontrase en el origen de la determinidad de mi consciencia. Yo no me percato de haberlo producido. Cuando comprendo la instrucción "piénsate a ti mismo», el concepto del yo me surge como algo inmediatamente dado, o bien como algo inmediatamente poseído, y esa es la razón por la que no me pregunto por el significado del concepto, la razón por la cual sé hacia donde orientar mi acto, ya que la determinidad de mi pensar (i.e., el concepto del yo que ha resultado de que me haya pensado a mí mismo) es el estado de reposo inmediato desde el que mi pensar se desprende en tanto que me determino a pensarme a mí mismo ${ }^{50}$.

Veámoslo una vez más. De algún modo, yo me encuentro en posesión del concepto del yo, y así logro comprender la instrucción y pensarme a mí mismo. Sin embargo, eso no quiere decir que yo sea consciente del modo como el concepto se ha constituido. Tener una comprensión natural o inmediata de este concepto no significa saber qué actos están envueltos en el proceso que tiene como resultado el que yo pueda comprenderlo. Yo estoy en posesión del concepto; sin embargo, lo que yo no tengo adquirido es el concepto del concepto ${ }^{51}$, el cual (al contrario del primero) no llego a poseer sin captar cómo lo he hecho y qué he hecho para hacerme consciente de él. Lo que me hace falta es, pues, la intuición de la actividad responsable de la formación del concepto.

Ahora bien, ya hemos visto que el concepto del yo sólo se constituye por medio del volverse sobre sí mismo del pensar y que dicha actividad no produce sino este

50 «... kurz, so wie du mich verstandest, war diese Bestimmtheit unmittelbar da. Darum verstandest du mich, und konntest deiner Thätigkeit, die ich auffoderte, die zweck[/]mäßige Richtung geben. Die Bestimmtheit deines Denkens durch das Denken deiner selbst war sonach, und musste nothwendig seyn, diejenige Ruhe, von der du dich zur Thätigkeit losrissest.», $V N D, G A$ I/4, 280.

${ }^{51}$ Véase ZE, GA, I/4, 257-259. 
mismo concepto. Por lo tanto, es necesario que dicha actividad haya ocurrido, es decir, resulta necesario que yo me haya pensado a mí mismo al comprender la instrucción "piénsate a ti mismo", esto es, resulta necesario que yo haya actuado o procedido de ese modo — aunque lo haya hecho sin haberlo percibido. Si el acto que está en el origen del concepto del yo conlleva un procedimiento necesario, entonces puedo percibir que la determinidad de mi pensamiento que es previa al acto libre de pensarme a mí mismo no puede ser explicada sino de este modo, y a pesar de que me parezca inmediatamente dado, el concepto del yo se ha constituido por medio de un acto que no he logrado empero intuir. Es decir, el estado de reposo previo al acto de pensarme a mí mismo - estado desde el cual mi pensar se desprende en tanto que se vuelve activo- tiene en su origen un acto que sólo es distinto del acto que consiste en pensarme a mí mismo en tanto que es un acto necesario y no un acto libre.

Por un lado, es verdad que en el exacto momento en que he comprendido el concepto (al escuchar la instrucción de pensarme a mí mismo), me he enterado de que mi pensar ya estaba determinado. Sin embargo, en ese momento no he reconocido que lo que estaba determinado era un acto, o más bien no he reconocido mi pensar como una actividad, sino como una determinidad o estado de reposo. Por otro lado, he logrado enterarme de la agilidad que corresponde al tránsito desde el estado de reposo al actuar mismo del pensar. Pero no he reconocido que en el momento mismo en que he comprendido el concepto yo haya actuado y procedido de aquel modo necesario que lo constituye. Al no prestar atención a esto último, sólo me he enterado del concepto ya constituido, o sea, de un estado de reposo que es la determinidad previa al desprendimiento del que me hago consciente en cuanto acto libre. $\mathrm{Al}$ no enterarme de dicha actividad pre-consciente que está a la base de la formación del concepto del yo, no he reconocido el concepto mismo en cuanto resultado de un acto o de un proceso de formación. Al no enterarme de dicha actividad en cuanto actividad (sino que la he aprehendido en cuanto estado de reposo), sólo me hago consciente de mí mismo en cuanto activo en el acto de desprendimiento de dicho estado de reposo (estado que precede el pensar el concepto del yo anteriormente constituido $)^{52}$.

52 «Um mich selbst als mich selbst setzend wahrnehmen zu können, mußte ich mich schon als gesetzt voraussetzen; zu der Thätigkeit [,] mit der ich mich setze, gieng ich über von einer Ruhe, Unthätigkeit, die ich der Thätigkeit entgegengesetze. Anderes konnte man die Vorstellung der Thätigkeit nicht merken; sie ist ein loßreißen von einer Ruhe, von welcher zur Thätigkeit übergegangen wird.», WLnm - K, GA IV/3, 348. 
Tal como Fichte nos dice, mientras he escuchado la instrucción y comprendido lo que tenía que hacer (pensarme a mí mismo), he actuado (o bien he procedido) de aquel modo que consiste en volverse sobre sí mismo, y lo he hecho inmediatamente - es decir, en el acto mismo de comprenderlo, yo mismo he producido el concepto de mí mismo. Esta actividad es la que está a la base de la formación del concepto que yo mismo produzco y comprendo, pero sin que me entere de que lo hago por mí mismo ${ }^{53}$. Por lo tanto, yo soy el que se da a sí mismo el concepto que corresponde a la determinidad previa al acto por medio del cual me desprendo de un estado de reposo para pensarme a mí mismo. Cuando presto atención al modo como logro pensarme a mí mismo, lo que hago no es sino lo mismo que ya había hecho, a saber, volverme sobre mí mismo. Pero entonces lo hago de un modo consciente, es decir, me entero de lo que estoy haciendo y, mientras lo hago, me hago consciente de mí mismo en cuanto activo (o sea, en cuanto soy yo el que de un modo libre me determino) ${ }^{54}$. Con el acto libre de prestar atención al acto necesario, comprendo finalmente lo que ha sucedido: comprendo que lo hago de nuevo, es decir, que de nuevo estoy actuando del único modo que me es posible pensarme a mí mismo - pero que ahora lo hago con consciencia y en libertad: ahora me entero de que soy yo el que produce el mismo concepto que antes encontraba ya constituido. Al prestar atención me entero de lo que está ocurriendo, es decir, me hago consciente de que soy yo el que lo estoy haciendo. $\mathrm{O}$ sea, al prestar atención al procedimiento necesario (i.e., al modo como tengo necesariamente que proceder para que se constituya para mí el concepto del yo), no sólo me entero de que repito lo que ya antes había hecho (aunque de manera inconsciente) sino que también adquiero el concepto del concepto ${ }^{55}$ y la clara comprensión de mí mismo en cuanto activo.

Ahora bien, según lo que hemos visto, parece que hay dos actividades distintas: una actividad necesaria y pre-consciente y otra libre, y que el concepto

53 «Oder, um die Sache deutlicher zu machen: — wie ich dir sagte: denke dich; und du das letztere Wort verstandest, vollzogst duim Actedes Verstehens selbst die in sich zurückgehende Thätigkeit, durch welche der Gedanke des Ich zu Stande kommt, nur ohne es zu wissen, weil du darauf nicht besonders aufmerksam warest; und daher kam dir das, was du in deinem Bewusstseyn vorfandest.», VND, GA I/4, 280.

54 «Merke auf, wie du das machst, sagte ich dir ferner; und nun vollzogst du dieselbe Thätigkeit, die du schon vollzogen hattest, nur mit Aufmerksamkeit und Bewusstseyn.», VND, GA I/4, 280.

${ }^{55}$ Véase $Z E$, GA, I/4, 257-259. 
del yo ocupa una posición central o intermedia entre estos dos momentos del «ser-activo». Pero en realidad sólo hay una única actividad que, por así decirlo, se desdobla en dos tiempos. El primero es el proceso de formación pre-consciente del concepto que tiene por resultado el estado de reposo y que corresponde a la constitución de la determinidad de la consciencia. El segundo es el acto por el cual el pensar se desprende de dicho estado de reposo y el yo se entera de sí mismo en cuanto libre al hacerse consciente del procedimiento por medio del cual se origina el concepto. La primera actividad es condición necesaria para que el concepto se constituya. La segunda consiste en traer ese mismo proceso a la consciencia. De modo que habría dos momentos de transición: uno desde la actividad necesaria al estado de reposo y otro desde el estado de reposo al actuar libre. Sin embargo, sucede que, porque yo no era consciente de aquella actividad necesaria que está en el origen de la constitución del concepto, tampoco me entero del movimiento de transición desde esa actividad al estado de reposo subsecuente, es decir, a la determinidad de mi consciencia que es previa al acto deliberado de pensarme a mí mismo. Mientras que en el segundo caso yo me entero de una discontinuidad entre el estado de reposo y el acto por medio del cual me determino a mí mismo a desprender mi pensar de la contemplación del concepto y a pensar el procedimiento que está a la base del concepto ya constituido. Por lo tanto, una vez que no me he enterado de la actividad que le precede - una vez que el proceso de su formación no es un proceso consciente-, tampoco me he enterado del movimiento de transición al estado de reposo desde un mínimo de actividad precedente ${ }^{56}$. El estado de reposo correspondiente al concepto del yo que constituye la determinidad de mi consciencia y desde el cual me sustraigo para pensarme a mí mismo - ese estado de reposo es para mí un «Faktum»: el estar dado inmediatamente para mí mismo es algo que yo no comprendo ni como resultado de un acto previo ni como algo que haya sido producido.

Ya en el segundo caso se puede hablar de una discontinuidad porque de una sola vez yo soy consciente del estado de reposo desde el que mi pensar se desprende para de nuevo volverse sobre sí mismo, y del movimiento de transición que consiste en el procedimiento de sustraerme a la determinidad previa de mi pensar para hacerme consciente de mí mismo —acto del cual me entero en cuan-

${ }^{56}$ Uno podría hablar de una instantaneidad del darse cuenta del concepto como concepto inmediatamente poseído (o bien de una quasi coincidencia entre la actividad y el resultado respectivamente producido). 
to que soy yo quien lo determino. Este acto me posibilita enterarme tanto del reposo previo como del desprendimiento, y por lo tanto me permite reconocer la diferencia y la determinación misma que está a la base de la consciencia de mí mismo en cuanto activo- mientras que en el otro caso yo sólo era consciente del concepto (i.e., del estado de reposo) y no de ninguna actividad que lo hubiera precedido (i.e., que hubiese alguna actividad en el origen de lo que inmediatamente encuentro como determinidad de mi pensamiento).

A pesar de todo ello, la actividad que está en el origen del proceso de formación del concepto del yo es una actividad que tiene lugar necesariamente puesto que de lo contrario yo no encontraría el concepto del yo ya constituido y, por así decirlo, ya siempre disponible (para poder pensarlo o reflexionar sobre ello). La cuestión ahora es la siguiente: ¿̨i dicha actividad es pre-consciente, cómo me hago consciente de ella? Ahora bien, si el concepto del yo sólo se constituye por medio de este volverse sobre sí misma de la actividad del pensar, reconozco en esa intuición el fundamento de la determinidad de la que me desprendo para hacerme consciente de mí mismo; gracias a esa intuición puedo reconocer que ese mismo acto (el acto de auto-posición del yo) tiene necesariamente que estar en el origen y a la base del concepto del yo empírico. Pero porque ese acto se ha realizado sin que fuese acompañado de la respectiva consciencia — porque ese acto es la condición de posibilidad necesaria de toda consciencia - yo no logro recuperarlo sino por medio de un acto reflexivo (por lo que yo no soy inmediatamente consciente de ese acto en cuanto acto; para enterarme de él, tengo que hacer algo para traerlo a mi consciencia $)^{57}$. Por lo tanto, que el filósofo no se entere inmediatamente de dicho acto en cuanto acto sino sólo en cuanto determinidad o hecho de consciencia no implica que no se trate de un acto - y además, de un acto necesario. Dicho acto es, por cierto, el acto de auto-posición del yo; o sea, es el acto originario por medio del cual el yo se constituye a la vez a sí mismo (es decir, el acto en que el yo se pone a sí mismo) y al mundo- el acto sin el cual el yo no podría hacerse consciente de

${ }^{57}$ Véase WLnm - K, GA IV/3, 328-329: «Es gibt 2 Haupthandlungen des Ich, die <eine> wodurch es sich selbst setzt und alles was dazu erforderlich ist, also die ganze Welt; die [zweite] ist ein abermaliges Setzen, desjenigen, was durch jene erste Handlung schon gesetzt ist. Es gibt also ein ursprüngliches Sezen des Ich und der Welt, und ein Setzen des schon Gesetzten, das erste macht das Bewusstseyn erst möglich, und kann daher darinn nicht vorkommen; das [zweite] aber ist das Bewusstseyn selbst. Das [zweite] sezt sonach das erste voraus. Im [zweiten] wird sonach etwas gefunden, als ohne Zuthun des Ich vorhanden, worauf das Ich REFLE[/]CTIRT.». 
sí mismo en cuanto puesto por sí mismo, es decir, el acto sin el cual el yo tampoco sabría de sí mismo en cuanto que es para sí mismo la unidad inmediata sujetoobjeto. Dicho acto es la condición necesaria de la autoconsciencia.

En otras palabras, con el intuirse a sí mismo el yo se entera de que es activo. Pero su auto-consciencia requiere su concepto (como condición de posibilidad de que el yo se entere de sí mismo). El concepto del yo es lo que está inmediatamente unido con el «ser-consciente» de sí mismo en cuanto activo ${ }^{58}$. El concepto del yo es la intuición misma de la actividad que consiste en el volverse sobre sí mismo. Dicho concepto es la actividad aprehendida, o sea, ya en estado de reposo y no en cuanto fuerza activa ${ }^{59}$. Por un lado, el concepto no es sino la intuición del yo. Por otro lado, el concepto es esa misma intuición, no en cuanto agilidad sino en cuanto determinidad de la consciencia del yo empírico. El concepto del yo no es sino el volverse sobre sí mismo del pensar - simplemente, aprehendido no como movimiento o agilidad sino como algo estable, inmóvil, (y no en cuanto activo). Si por un lado sólo el concepto puede ser pensado (la actividad no puede sino ser intuida), por otro lado el objeto de la actividad que se vuelve sobre sí misma es la actividad misma, por lo que dicha actividad se intuye a sí misma en acto - a pesar de que al aprehenderse, dicha actividad se detenga y se vuelva fija. De este modo, según Fichte, se explica que el yo en cuanto activo (i.e., en cuanto sujeto) y el yo en cuanto concepto (i.e., en cuanto objeto) coincidan uno en el otro - o mejor dicho, sean lo mismo (la unidad sujeto-objeto, autoconsciencia) - simplemente, vistos de modo distinto ${ }^{60}$.

Fichte termina el fragmento de su nueva tentativa de exposición recordándonos que en la consciencia objetiva (o bien en la consciencia reflexiva) uno no

${ }^{58}$ «Man nennt die innere Thätigkeit in ihrer Ruhe aufgefasst, durchgängig den Begriff. Es war sonach der Begriff des Ich, der mit der Anschauung desselben nothwendig vereinigt war, und ohne welchen das Bewusstseyn des Ich unmöglich geblieben wäre; denn der Begriff erst vollendet und umfasst das Bewusstseyn.», VND, GA I/4, 280.

${ }^{59}$ "Man nennt die innere Thätigkeit in ihrer Ruhe aufgefasst, durchgängig den Begriff.», $V N D$, GA I/4, 280.

${ }^{60}$ «Der Begriff ist überall nichts anders, als Thätigkeit des Anschauens selbst, nur nicht als Agilität, sondern als Ruhe und Bestimmtheit aufgefasst; und so verhält es sich auch mit dem Begriffe des Ich. Die in [/] sich zurückgehende Thätigkeit als feststehend und beharrend aufgefasst, wodurch sonach beides, Ich, als Thätiges, und Ich, als Object meiner Thätigkeit, zusammen fallen, ist der Begriff des Ich.», VND, GA I/4, 280. 
logra encontrar sino los conceptos, y nunca las respectivas intuiciones con independencia de ellos — es decir, las intuiciones mismas—; y esto a pesar de que los conceptos se forman sobre la base de dichas intuiciones, sin que nos enteremos de lo que está ocurriendo. Por lo tanto, hace falta elevarse a otro tipo de consciencia: a la consciencia de la intuición misma - y eso sólo podemos hacerlo si actuamos en libertad, si nos determinamos nosotros mismos a pensar los actos necesarios envueltos en la producción de los conceptos que siempre ya encontramos dados y disponibles. El saber qué dirección dar a nuestro pensar —el saber cómo proceder- sólo es posible porque las intuiciones de las que somos conscientes siempre están ya acompañadas por (o conectadas con) un determinado concepto. Este concepto nos señala la dirección que el acto libre tiene que tomar para pensar la intuición de la que no hemos logrado hacernos conscientes. Sólo así se explica —y sólo así se comprende— por qué el objeto de la intuición nos parece previo a la intuición misma: porque dicho objeto no es sino la intuición (simplemente, aprehendida en su forma fija, o sea, no en cuanto actividad, sino en tanto que concepto ${ }^{61}$.

${ }^{61}$ Véase VND, GA I/4, 280-281. 